\title{
REPERENCE
}

NISTIR 89-4106

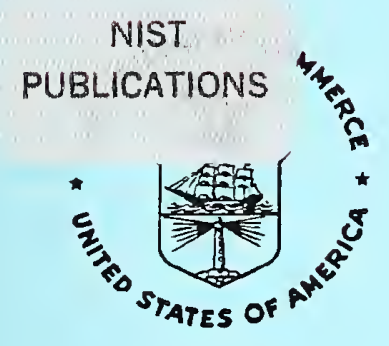

\section{Site Characterization for Radon Source Potential}

\author{
Felix Y. Yokel
}

U.S. DEPARTMENT OF COMMERCE

National Institute of Standards and Technology

National Engineering Laboratory

Center for Building Technology

Gaithersburg, MD 20899

June 1989

Prepared for:

Department of Housing and Urban Development Innovative Projects and Special Technology Division

Washington, DC 20410

State of New Jersey

Division of Housing and Development

Trenton, NJ 08625-0802

The Ryland Group, Inc.

Columbia, MD 21044

$-Q C$

100

.456

89-4106

1989

C.2 



\section{NISTIR 89-4106}

\section{Site Characterization for Radon Source Potential}

Felix Y. Yokel

U.S. DEPARTMENT OF COMMERCE

National Institute of Standards and Technology

National Engineering Laboratory

Center for Building Technology

Gaithersburg, MD 20899

June 1989

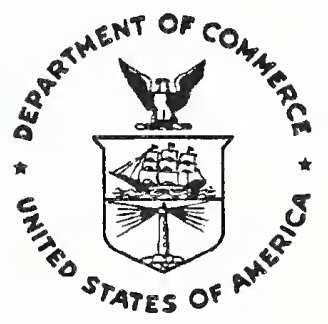

National Bureau of Standards became the National Institute of Standards and Technology on August 23, 1988, when the Omnibus Trade and Competitiveness Act was signed. NIST retains all NBS functions. Its new programs will encourage improved use of technology by U.S. industry.

Prepared for:

Department of Housing and Urban Development Innovative Projects and Special Technology Division

Washington, DC 20410

State of New Jersey

Division of Housing and Development

Trenton, NJ 08625-0802

The Ryland Group, Inc. Columbia, MD 21044

\section{U.S. DEPARTMENT OF COMMERCE}

Robert Mosbacher, Secretary NATIONAL INSTITUTE OF STANDARDS 


\section{ABSTRACT}

Radon source potential characterization of sites in terms of soil index properties which do not vary with transient conditions such as moisture content, barometric pressure, temperature and wind speed is studied. The invariant index properties which were found to be critical for site characterization are radium activity concentration in the soil, in-place dry density, porosity, and dry gas permeability. These properties can be measured in situ or in the laboratory, or estimated on the basis of other soil index properties such as grain-size distribution and Atterberg limits. Various expressions for radon source potential are reviewed and a new expression is formulated on the basis of data from areas of deep glacial terrace deposits. Site exploration methods proposed include use of the standard Penetration Test together with a laboratory determination of radium activity concentration, and a rapid field measurement procedure using a portable gamma ray spectrometer, a portable nuclear moisturedensity meter and retrieval of a soil sample for laboratory determination of particle-size distribution. A plan to develop exploration protocols, test the effectiveness of the source potential prediction, and prepare a draft exploration standard is proposed.

Keywords: convective flow; diffusion; insitu measurements; soil exploration; permeability; porous media; radium activity concentration; radon; radon source potential. 
1. INTRODUCTION

2. RADON PRODUCTION AND TRANSPORT IN SOILS $\ldots \ldots \ldots \ldots \ldots \ldots \ldots$

2.1 Radon Production in Soils $\ldots \ldots \ldots \ldots \ldots \ldots \ldots \ldots$

2.2 Radon Transport $\ldots \ldots \ldots \ldots \ldots \ldots \ldots \ldots \ldots \ldots$

3. VARIABLES AND THEIR MEASUREMENT $\ldots \ldots \ldots \ldots \ldots \ldots \ldots$

3.1 Radon Generation in Soil Pores $\ldots \ldots \ldots \ldots \ldots \ldots \ldots$

3.2 Radon Transport in Soils $\ldots \ldots \ldots \ldots \ldots \ldots \ldots \ldots \ldots$

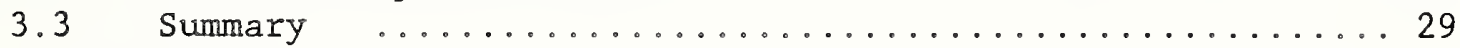

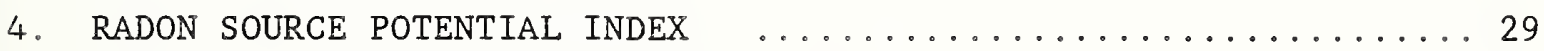

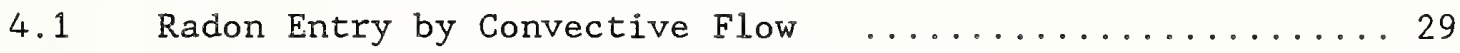

4.2 Expressions For Radon Source Potential ........... 33

5. SITE EXPLORATION FOR RADON SOURCE POTENTIAL $\ldots \ldots \ldots \ldots \ldots \ldots$

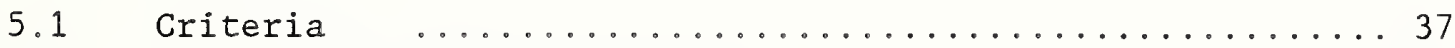

5.2 Options For Site Exploration $\ldots \ldots \ldots \ldots \ldots \ldots \ldots \ldots$

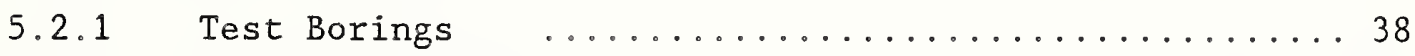

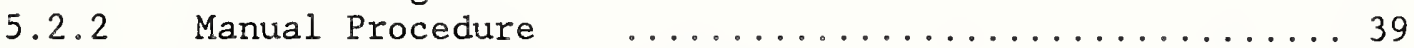

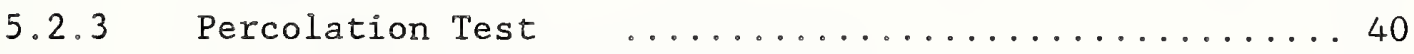

5.2 .4 Existing Radon Testing Protocols ........... 40

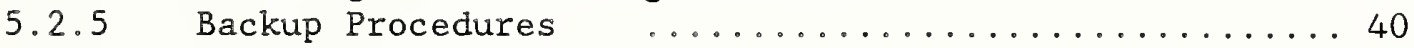

5.3 Selection of Exploration Procedure $\ldots \ldots \ldots \ldots \ldots \ldots$

6. STANDARD DEVELOPMENT $\ldots \ldots \ldots \ldots \ldots \ldots \ldots \ldots \ldots \ldots \ldots \ldots \ldots \ldots \ldots \ldots$

7. ACKNOWLEDGEMENT $\ldots \ldots \ldots \ldots \ldots \ldots \ldots \ldots \ldots \ldots \ldots \ldots \ldots \ldots$

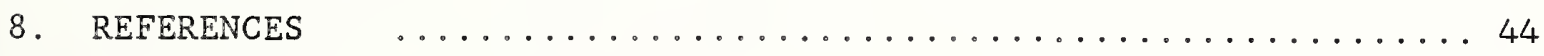


vi 


\section{LIST OF SYMBOLS}

$\mathrm{A}_{\mathrm{Ra}}=$ radium activity concentration in the soil $\left(\mathrm{Bq} \cdot \mathrm{kg}^{-1}\right)$

$\mathrm{C}=$ radon concentration in soil $\operatorname{gas}\left(\mathrm{Bq} \cdot \mathrm{m}^{-3}\right)$

$\mathrm{Cm}_{\mathrm{a}}=$ measured radon concentration in soil gas $\left(\mathrm{pCi} \cdot \mathrm{l}^{-1}\right)$

$\mathrm{C}_{\max }=$ maximum possible radon concentration in the soil gas

$\mathrm{Cu}=\frac{\mathrm{d}_{60}}{\mathrm{~d}_{10}}=$ uniformity coefficient of particle size distribution

$c$ = coefficient in the Hazen formula

$D$ = bulk diffusivity coefficient in soil matrix $\left(\mathrm{m}^{2} \cdot \mathrm{s}^{-1}\right)$

$D_{e}=$ effective (interstitial) diffusion coefficient $\left(\mathrm{m}^{2} \cdot \mathrm{s}^{-1}\right)$

$\mathrm{d}=$ geometric mean particle diameter (by size)(m)

$\mathrm{d}_{10}=$ the particle size which is equal or larger than $10 \%$ of the particles by weight or "effective particle size" (m)

$\mathrm{d}_{60}=$ the particle size which is equal or larger than $60 \%$ of the particles by weight (m)

e = void ratio (dimensionless)

$\mathrm{F}=$ radon source potential (Nazaroff \& Sextro, $\mathrm{Bq} \cdot \mathrm{s}^{-1}$ )

$\mathrm{f}=$ Emanation Coefficient (dimensionless)

$\mathrm{G}=$ Volumetric Radon Generation in Soil Pores $\left(\mathrm{Bq} \cdot \mathrm{m}^{-3} \cdot \mathrm{s}^{-1}\right) *$

$\mathrm{H}=$ height below soil surface (m)

$\mathrm{h}=$ air change period (h)

$\mathrm{J}=\operatorname{radon} \operatorname{flux}\left(\mathrm{Bq} \cdot \mathrm{s}^{-1} \cdot \mathrm{m}^{-2}\right)$

$k$ = coefficient of gas permeability $\left(\mathrm{m}^{2}\right)$

$\mathrm{k}_{\mathrm{m}}=$ measured coefficient of gas permeability in $\left(\mathrm{m}^{2}\right)$

$k_{w}=$ Darcy's water permeability coefficient $\left(\mathrm{m} \cdot \mathrm{s}^{-1}\right)$

$L=$ length of the perimeter crack (m)

$\ell=$ diffusion length (m)

$\mathrm{m}$ = degree of saturation as a fraction of pore space (dimensionless)

$\mathrm{M}$ = mean migration distance (Tanner, $\mathrm{m}$ )

$\mathrm{n}$ = porosity of soil (dimensionless)

$\mathrm{P}_{\mathrm{o}}=$ mean atmospheric pressure $(\mathrm{Pa})$

$* 1 \mathrm{~Bq}$ corresponds to the emission of 1 radon atom per second ( $1 \mathrm{~g}$ of radium emits $3.7 \cdot 10^{10} \mathrm{~Bq}$ or $\left.1 \mathrm{Cu}\right)$. 


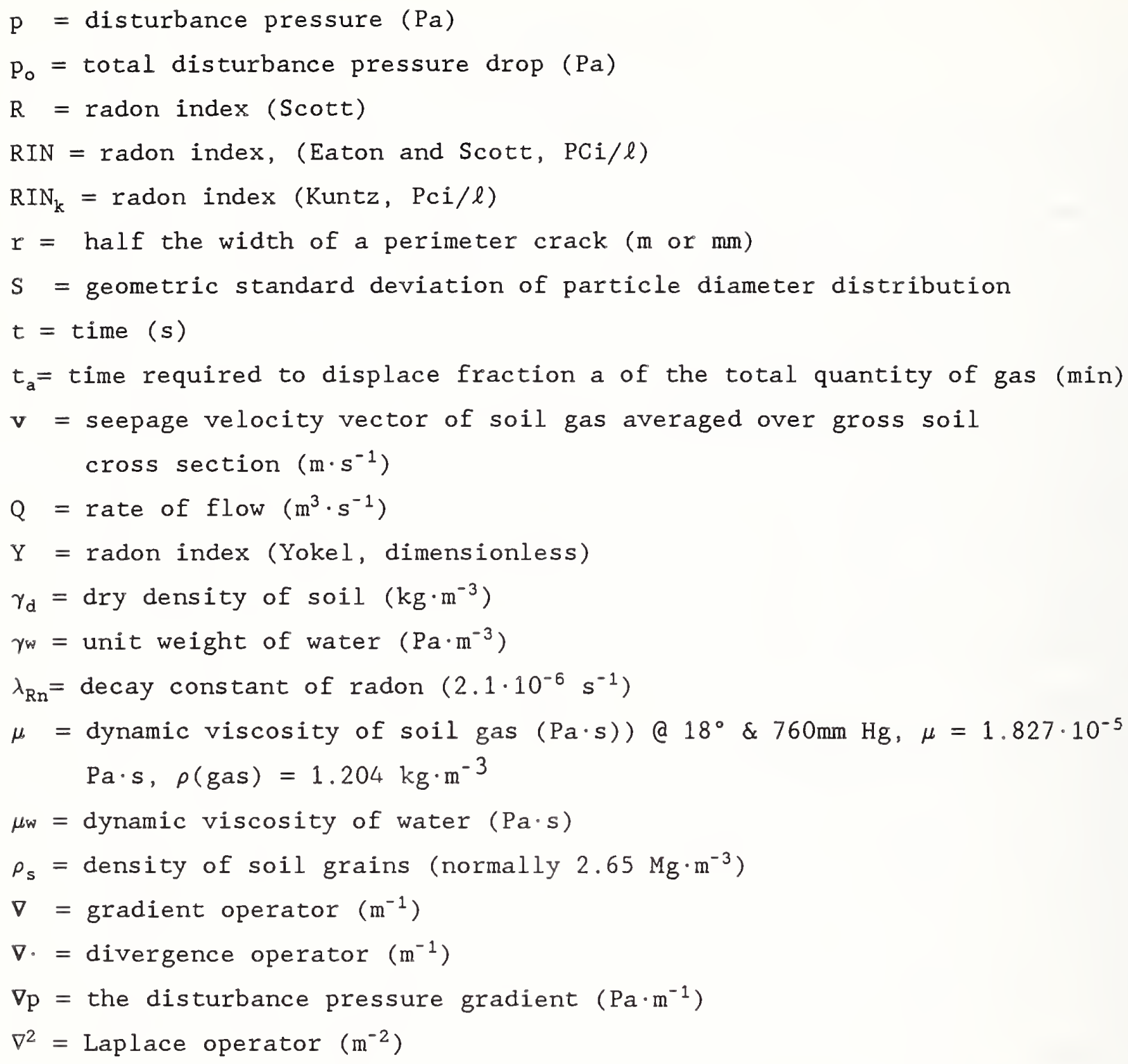




\section{EXECUTIVE SUMMARY}

There is a need to identify and measure site characteristics which contribute to the emission of radon gas into the interior of buildings. In present practice this is usually attempted by insitu measurements of gas permeability and radon activity concentrations in the soil gas. These measurements are sensitive to transient conditions prevailing at any point in time: the gas permeability is sensitive to soil moisture content; and the radon activity concentration in the soil gas is sensitive to variations in soil moisture content, atmospheric pressure, temperature gradients and wind speed. However, there are measurable invariant soil index properties (independent of moisture content and atmospheric conditions) which are related to the propensity of sites to generate and transport radon gas over time. This report deals with the site characterization for radon source potential using these invariant soil index properties. The advantage of this approach is that the measurements performed in a site exploration are repeatable, a necessary pre-condition for any measurement associated with a standard, and that the calculated source potential represents the propensity for radon generation, rather than the radon generation under a specific set of conditions, which may be transient. The site exploration procedures considered utilize established soil exploration and classification techniques to the maximum extent possible.

The most important invariant soil properties identified are radium activity concentration $\left(A_{R a}\right)$, in-place dry density and porosity of the subsoil $\left(\gamma_{d}, n\right)$, and the dry gas permeability coefficient of the subsoil ( $k$ ). These quantities eithex can be measured or estimated on the basis of soil index properties. Quantities $A_{R a}, \gamma_{d}$ and $n$ can be measured directly by various field and laboratory techniques. The permeability, $k$, can be estimated on the basis of grain size distribution, which in turn can be measured by established procedures. An insitu value of $\mathrm{k}$ (not corrected for moisture content) is presently measured by air injection or soil gas extraction. This measurement is strongly dependent on moisture content. In most instances a correction for the moisture content would have to be made if this measurement is used to determine dry gas permeability. While equations which correlate soil moisture content with gas permeability have been developed, presently available information does 
not provide a reliable basis for a moisture-content correction of gas permeability without the aid of additional, sophisticated laboratory tests. Alternately, the coefficient of gas permeability can be derived from that for saturated water permeability, which in turn can be measured in the field and in the laboratory.

Several expressions for radon source potential have been proposed (Equations 28 , $29,30,32$, and 33). An additional expression (equation 31) is proposed in this paper on the basis of data from New York State (Kuntz et al., 1988). The dimensional correlation between the permeability and radon entry depends on whether the radon transport by convective flow is dominated by transient or by steady-state flow conditions. Several of the proposed expressions are derived from steady-state flow conditions. However available data indicate that the radon concentration is approximately proportional to $k^{0.5}$ (for instance Kuntz et al. 1988, Scott, 1985), a dimensional correlation which is closer to that predicted by transient flow conditions. There are insufficient data to draw conclusions, because it is difficult to separate the effect of $k$ from that of other variables.

Some of the proposed expressions for radon source potential use invariant soil properties, while others are linked with site exploration procedures which measure in-place gas permeability and radon activity concentration in the soil gas without consideration of transient conditions. All these expressions could be modified to utilize measured invariant soil properties with a proper allowance for the effect of soil moisture content.

Two exploration procedures are proposed: (1) exploration by traditional test boring methods, such as the Standard Penetration Test, supplemented by $\boldsymbol{\gamma}$ spectroscopy to determine $A_{R a}$ and by a procedure to identify finegrained soils which are likely to develop fissures; and (2) a rapid field exploration procedure using a portable spectrometer to determine $A_{R a}$, a portable nuclear moisture-density gage to determine $\gamma_{d}$ and natural moisture content, and retrieval of a small soil sample for laboratory particle-size analysis and indirect determination of $k$. It is suggested that this latter field procedure could be combined with conventional percolation tests to provide more accurate 
information on permeability. Whether method (1) or (2) is used would depend on the scale of the exploration (one building or many buildings) and on the need for geotechnical data for other purposes (i.e. method (1) would be used if soil borings are also needed for other purposes).

A plan for further studies is proposed in order to develop exploration protocols, test the validity of radon source potential predictions, and prepare a draft standard. 
xii 


\section{INTRODUCTION}

Soil and rock have been identified as the most important source of radon to which people are exposed [Nazaroff et al., 1988]. It is, therefore, important to identify the site characteristics which contribute to the transport of radon gas into the interior of buildings. The indoor radon level in a building depends on the potential of the site to emit radon, and on the characteristics of the building and its HVAC system. Thus a true measure of the radon source potential for a building must consider site, as well as building characteristics. This report deals only with site characterization.

Presently used site characterization methods employ various techniques to measure two quantities: the radon concentration in the soil gas; and the gas permeability of the soil on the building site [Tanner, 1988; Sextro et al.; 1988; Kunz et al., 1988]. The measurement of these quantities is sensitive to transient conditions. The radon activity concentration in the soil gas at any point in time depends on the radon flux, which in turn is influenced by variations and the rate of change in barometric pressure, soil moisture content, wind velocity, and temperature. In addition, the radon activity concentration in the soil gas is also sensitive to barometric pressure changes, rainfall, and temperature variations prior to its measurement [i.e. Schumann et al., 1988]. The gas permeability of the soil varies with the moisture content, which in turn varies seasonally and could be changed by future site development.

The objective of this study is to assess the possibility of developing a site characterization procedure which is based on measurements which are not sensitive to transient conditions. Consideration is also given to the development of procedures which will utilize established soil exploration and classification techniques to the maximum extent possible. Equations for radon production and transport are reviewed in Section 2 and some solutions are presented. The variables in these equations and their measurement are discussed in Section 3. In Section 4 various expressions for radon source potential are reviewed and a new expression is proposed on the basis of data from New-York State. Options for site exploration are discussed in Section 5. A plan for standard development is presented in section 6 . 


\section{RADON PRODUCTION AND TRANSPORT IN SOILS}

\subsection{Radon Production in Soils}

The volumetric radon generation rate in the soil pores can be determined by the following equation [Nazaroff et al., 1988, p.85]:

$$
G=\left(f \rho_{s} A_{R a} \lambda_{R n}\right) \frac{1-n}{n} \quad \ldots
$$

where: $\quad G=$ volumetric radon generation in soil pores $\left(B q \cdot \mathrm{m}^{-3} \mathrm{~s}^{-1}\right) *$

$\mathrm{f}=$ emanation coefficient (dimensionless)

$\mathrm{A}_{\mathrm{Ra}}=$ radium activity concentration in the soil $\left(\mathrm{Bq} \cdot \mathrm{kgl}^{-1}\right)$

$\rho_{\mathrm{s}}=$ density of soil grains (normally $2.65 \mathrm{Mg} \cdot \mathrm{m}^{-3}$ )

$\lambda_{\mathrm{Rn}}=$ decay constant of radon $\left(2.1 \cdot 10^{-6} \mathrm{~s}^{-1}\right)$

$\mathrm{n}$ = porosity of soil (dimensionless).

$* 1 \mathrm{~Bq}$ corresponds to the emission of 1 radon atom per second ( $1 \mathrm{~g}$ of radium emits $3.7 \cdot 10^{10} \mathrm{~Bq}$ or $\left.1 \mathrm{Cu}\right)$.

Equation (1) can be re-written as:

$$
G=\left(f \gamma_{d} A_{R a} \lambda_{R n}\right) \frac{1}{n} \ldots(2)
$$

where: $\gamma_{d}=$ dry density of $\operatorname{soil}\left(\mathrm{kg} \cdot \mathrm{m}^{-3}\right)$

In the absence of any radon flux (say at a very great depth) the rate of volumetric radon generation equals the rate of radon decay:

$$
\left(f \gamma_{d} A_{R a} \lambda_{R n}\right) \frac{1}{n}=\lambda_{R n} C
$$

Therefore:

$$
C=C_{\max }=\frac{G}{\lambda_{R n}}=\left(f \gamma_{d} A_{R a}\right) \frac{1}{n}
$$

where:

$$
\begin{aligned}
& \mathrm{C}=\text { radon activity concentration in soil gas }\left(\mathrm{Bq} \cdot \mathrm{m}^{-3}\right) \\
& \mathrm{C}_{\max }=\text { maximum possible radon activity concentration in the soil gas }
\end{aligned}
$$




\subsection{Radon Transport}

The following general equation can be written for the radon concentration field in the soil (averaged over the total soil volume) [Oliveira Lourero, 1987]:

$$
\frac{\partial}{\partial t}(C n)=\nabla \cdot(D \nabla C)-\nabla \cdot(v C)+n\left(G-\lambda_{R_{n}} C\right) \ldots(5)
$$

where: $\quad \nabla=$ gradient operator $\left(\mathrm{m}^{-1}\right)$

$$
\begin{aligned}
\nabla \cdot= & \text { divergence operator }\left(\mathrm{m}^{-1}\right) \\
\mathrm{D}= & \text { bulk diffusivity coefficient in soil matrix }\left(\mathrm{m}^{2} \cdot \mathrm{s}^{-1}\right) \\
\mathbf{v}= & \text { seepage velocity vector of soil gas averaged over gross soil } \\
& \text { cross section }\left(\mathrm{m} \cdot \mathrm{s}^{-1}\right)
\end{aligned}
$$

Eq (5) is for the transient case, where there is a spacial variation of radon activity concentration with time. For steady-state conditions:

$$
\frac{\partial(\mathrm{Cn})}{\partial t}=0
$$

The first term on the right side of $\mathrm{Eq}$ (5) deals with diffusive transport which follows Fick's law and can be modeled by the following equation:

$$
\frac{\partial(\mathrm{Cn})}{\partial t}=\mathrm{D} \nabla^{2} \mathrm{C}-\mathrm{n}\left(\lambda_{\mathrm{Rn}}-\mathrm{G}\right) \quad \ldots(7)
$$

A solution for the steady-state diffusion from a semi-infinite homogeneous soil mass with an activity concentration $C=C_{\max }$ at a great depth and an activity concentration $C=0$ at the surface is given by the following equation for $C$ at depth $z$ below the surface [Clements, 1974]:

$$
C(z)=C_{\max }\left[1-\exp \left(-\frac{z}{l}\right)\right]
$$

where:

$$
l=\left(\frac{\mathrm{D}}{\mathrm{n} \lambda_{\mathrm{Rn}}}\right)^{0.5}
$$

The radon flux at the surface resulting from the spacial distribution of $C$ in Eq (8a) is:

$$
\mathrm{J}_{\mathrm{dz}}=\mathrm{n} \lambda_{\mathrm{Rn}} \ell \mathrm{C}_{\max }
$$


where $\ell$ is known as the "diffusion length" and is typically $1 \mathrm{~m}$. A typical value for $D_{e}=D / n$, the "interstitial" (or "effective") diffusion coefficient for radon in soils of low moisture content is on the order of $10^{-6} \mathrm{~m}^{2} \mathrm{~s}^{-1}$ [Nazaroff and Nero, 1988]. In saturated soil the coefficient may be reduced to the much lower value of $2 \cdot 10^{-10} \mathrm{~m}^{2} \mathrm{~s}^{-1}$. An equation predicting the diffusion coefficient as a function of porosity $(n)$ and saturation (m) has been proposed by Rogers and Nielson, 1988:

$$
D_{e}=7 \cdot 10^{-6} \exp \left[-4\left(m-m^{2}-m^{5}\right)\right] \text { in } \mathrm{m}^{2} \cdot \mathrm{s}^{-1}
$$

The latter equation yields a value of $7 \cdot 10^{-6} \mathrm{~m}^{2} \cdot \mathrm{s}^{-1}$ for dry soils. In the same reference another, modified equation is proposed for highly compacted soils. Eq (9) is empirical and was obtained by fitting experimental data.

The second term on the right side of Eq (5) deals with convective flow of soil gas, the most important transport mechanism contributing to the entry of radon gas into buildings. Within the range of pressure gradients and soil particle size distributions which is of practical interest in conjunction with the radon transport problem, it is reasonable to assume that convective soil-gas transport can be modeled by Darcy's law [Darcy, 1856], which is valid when the flow is laminar and the flow resistance is frictional. The upper limit to the validity of Darcy's law would occur at high Reynold's numbers where the laminar flow breaks down and becomes turbulent. This limit has been observed to be exceeded in gas flow through soils at relatively high induced pressure gradients [Matthews et al., 1988]. However, since Reynold's Number is directly proportional to flow velocity, and velocities are small when the induced pressure gradients are small, the laminar flow limit is not likely to be exceeded in the flow conditions under consideration even in gravelly soils. There is some evidence [Hansbo, 1960] that for the flow of pore water there is a lower limit when particle sizes are very small (some clays) and surface chemistry, rather then friction provides most of the flow resistance. This range, if applicable to the flow of soil gas, is also not of interest, because flow velocities in very finegrained soils are very small and the dominant mechanism of radon transport is diffusion.

For flow of gases through a porous medium Darcy's law can be written as:

$$
\mathrm{v}=-\left(\frac{\mathrm{k}}{\mu}\right) \nabla \mathrm{p}
$$


where: $\mathrm{k}=$ coefficient of gas permeability $\left(\mathrm{m}^{2}\right)$

$$
\begin{aligned}
\mu= & \text { dynamic viscosity of soil gas }(\mathrm{Pa} \cdot \mathrm{s})) \\
& \quad 18^{\circ} \& 760 \mathrm{~mm} \mathrm{Hg}, \mu=1.827 \cdot 10^{-5} \mathrm{~Pa} \cdot \mathrm{s}, \rho(\text { gas })=1.204 \mathrm{~kg} \cdot \mathrm{m}^{-3} \\
\nabla_{\mathrm{p}}= & \text { the disturbance pressure gradient }\left(\mathrm{Pa} \cdot \mathrm{m}^{-1}\right)
\end{aligned}
$$

The concept of disturbance pressure used in Eq (10) is similar to the concept of "excess pore water pressures" used in geotechnical engineering. Consequently, disturbance pressure is defined as the difference between the pressure prevailing at any point in the soil and the atmospheric pressure for the point (which increases with depth).

If it is assumed that the disturbance pressures in the soil gas are small in comparison with the prevailing atmospheric pressure, that there are no significant temperature variations within the space considered which could influence soil gas pressures, and that the soil is homogeneous and isotropic with respect to permeability, the following general equation applies to pressure-gradient induced convective flow of soil gas [Fukuda, 1955]:

$$
\frac{k P_{0}}{\mu \mathrm{n}} \nabla^{2} \mathrm{p}=\frac{\partial \mathrm{p}}{\partial \mathrm{t}}
$$

This equation applies to the transient condition, where the pressure distribution changes with time. For steady-state flow conditions (when pressure differentials prevail long enough for the gradients to stabilize), this equation becomes:

$$
\nabla^{2} \mathrm{p}=0 \text {, or when } \mathrm{k} \text { is not constant: } \nabla \cdot(\mathrm{k} \nabla \mathrm{p})=0
$$

Two solutions to Eq (11) are examined below. Schery et al., 1984, present the "steady-state" (stabilized) solution to a sinusoidal pressure pulse:

$$
\text { if: }
$$

$$
\mathrm{p}=\mathrm{p}_{\mathrm{o}} \sin \omega t \text { and } \mathrm{p}_{\mathrm{o}} \ll \mathrm{P}_{\mathrm{o}}
$$

then:

$$
v_{z}(z=0, t)=p_{0}\left(\frac{k n \omega}{P_{\mathrm{o}} \mu}\right)^{0.5} \sin \left(\omega t-135^{\circ}\right)
$$

where: $\quad \mathrm{P}_{0}=$ mean atmospheric pressure

$$
\mathrm{p} \text { = disturbance pressure }
$$


Another case of interest is an atmospheric disturbance pressure, $p_{0}$, applied at time $t=0$ at the surface of a soil layer of infinite depth. The disturbance pressures and convective flow velocities (or convective flux) as a function of depth $z$ at any time, $t$, can be derived from a solution to the general heat equation presented by Carslaw and Jaeger, 1959, p 60, equations (5) to (8):

$$
\begin{gathered}
\frac{\mathrm{p}(\mathrm{z})}{\mathrm{P}_{0}}=\operatorname{erf}\left[\frac{z}{2}\left(\frac{\mu \mathrm{n}}{\mathrm{kP} \mathrm{P}_{0}}\right)^{0.5} \cdot \mathrm{t}^{-0.5}\right] \\
\mathrm{v} z_{2}(z=0, t)=v_{0}=-\mathrm{P}_{0}\left(\frac{\mathrm{kn}}{\pi \mu \mathrm{P}_{0}}\right)^{0.5} \cdot t^{-0.5}
\end{gathered}
$$

and

$$
v_{z}(z, t)=v_{0} \cdot \exp \left(\frac{\mu n z^{2}}{4 k P_{0} t}\right)
$$

When a layer of depth $\mathrm{H}$ resting on an impervious base is substituted for the infinite depth in the previous solution, the following expressions are derived from an approximate solution of the one-dimensional consolidation equation [Terzaghi, 1942]. If it is assumed that at constant temperature the volume of pore gas is inversely proportional to the pressure (Boyle's law), then the volume of gas displaced by a disturbance pressure po from a column of soil of unit cross section area and height $\mathrm{H}$ is:

$$
\Delta V=\frac{n H p_{0}}{P_{0}}, P_{0} \ll P_{\circ}
$$

and for the following conditions:

If: $t<0 ; P=P_{0}$ for all values of $z$

$$
0 \leq t<0.413 \frac{\mathrm{H}^{2} \mu \mathrm{n}}{\mathrm{kP}_{\mathrm{o}}} \text { and } \mathrm{z}=0 ; \mathrm{P}=\mathrm{P}_{\mathrm{o}}-\mathrm{P}_{\mathrm{o}}
$$

then:

$$
\int_{0}^{t} v_{z}(z=0, \tau) d \tau \simeq-2 \mathrm{p}_{\circ}\left(\frac{k n}{\pi \mu \mathrm{P}_{\circ}} t\right)^{0.5}
$$

Differentiating: $\quad v_{z}(z=0, t) \simeq-p_{0}\left(\frac{k n}{\pi \mu P_{0}}\right)^{0.5} \cdot t^{-0.5}$

Equation 17 is for the total radon flux from $t=0$ to $t$. The negative sign in Eqs.(15) and (17) indicates that the flow velocity, $v$, is in a direction of decreasing values of $z$. From the differentiation of Eq.(17) it can be concluded that the equation is an exact solution for a layer of infinite depth. 
However, in accordance with Terzaghi, 1942, it is only valid for the time increment indicated if the depth of the layer is limited. Solutions for the transient flow condition and other boundary conditions of interest, such as cylindrical and spherical surfaces in an infinite mass can be found in Carslaw and Jaeger, 1948, pp 334-337, and a solution for a linearly changing surface pressure, $p=a t$, where a is a constant, was presented by Clements, 1974.

In contrast to the solutions for Eq (11) obtained in Eqs.(15) through (17), Equation (12) would apply if the pressure difference between the pore pressures in the surrounding soil mass and the interior of the building persists for a long period of time, so that pressure gradients can stabilize. Steady-state solutions were developed for many boundary conditions using the semi-graphical technique of flow nets [i.e. Cedergren, 1967, Harr, 1962], and other techniques, such as the method of "fragments" [Pavlovski, 1956, Harr, 1962], or appropriate computer programs. Some closed-form solutions were also developed [i.e. Dupuis, 1863]. A solution which seems appropriate for the radon entry into basements was presented by DSMA ADCON Ltd., 1983, based on an analogy between Ohm's law. The same equation is also used by Mowris and Fisk, 1988, to calculate radon entry rates into houses. If it is assumed that radon entry is through a linear gap between the basement slab and the perimeter wall, then:

$$
\mathrm{Q}=\frac{\pi \mathrm{Lkp}_{\circ}}{\mu \cosh ^{-1}(\mathrm{D} / \mathrm{a})}
$$

where: $Q=$ rate of flow $\left(\mathrm{m}^{3} \cdot \mathrm{s}^{-1}\right)$

$\mathrm{p}_{\mathrm{o}}=$ total pressure difference $(\mathrm{Pa})$

$\mathrm{a}=$ half width of the crack (m)

$D=$ depth below surface $(m)$

$\mathrm{L}=$ length of crack $(\mathrm{m})$

DSMA ADCON make the case that for $D>0.5 \mathrm{~m}$ and a crack width of $10^{-3} \mathrm{~m}$ which is typical for anticipated conditions this equation is not very sensitive to depth change. If $\mu$ is taken as $1.8 \cdot 10^{-5} \mathrm{~Pa} \cdot \mathrm{s}$, and $\cosh ^{-1}(\mathrm{D} / \mathrm{a})$ as $\geq 8.3$, then:

$$
\mathrm{Q} \leq \frac{k \mathrm{~L} \mathrm{p}_{\mathrm{o}}}{4.8 \cdot 10^{-5}} \mathrm{~m}^{3} \mathrm{~s}^{-1}
$$


Since this model does not account for the geometry of the house foundation it is suggested by DSMA ADCON to add $1.5 \mathrm{~m}$ to the depth of the crack to account for the foundation. The authors justify the recommendation by a graphical construction of flow lines.

Steady-state flow is also assumed in a finite difference model developed by Oliveira-Loureiro, 1987. This model considers several parameters simultaneously by solving $\mathrm{Eq}(5)$ in a soil block extending $10 \mathrm{~m}$ from the outer walls of the building. A sensitivity study is then conducted varying one parameter at a time while the other parameters are kept constant. Permeability is one of the parameters. As expected, it was concluded that if soil permeability were the only factor affecting the soil-gas flow there would be a linear correlation between soil-gas flow and permeability $k$. But the soil-gas flow and the radon flux are also affected by other variables which are subsequently discussed. It must be noted, however, that the findings of the study have no experimental verification, that a steady-state flow model was used which represents a lower bound for convective-flow effects and that many other simplifying assumptions were made. Thus the conclusions are at best qualitative.

First, convective-flow effects are limited by the soil-gas entry mechanism. The study assumed a crack and varied the crack width from 0.5 to $10 \mathrm{~mm}$. It was found that only for cracks wider than $5 \mathrm{~mm}$ was there no significant pressure drop across the crack. For crack widths smaller than $1 \mathrm{~mm}$ the crack width as well as $k$ affected the flow volume for $k \geq 10^{-11} \mathrm{~m}^{2}$. Furthermore, the diffusive component of $\mathrm{Eq}(5)$ dominated the radon flux for $\mathrm{k} \leq 10^{-12} \mathrm{~m}^{2}$. For soil permeabilities $k \geq 10^{-11}$ to $10^{-10}$ dilution of the radon concentration in the soil gas became significant and was very significant at the upper limit of this permeability range. Thus it can be seen that even with a steady-state flow model, radon flux was a linear function of $k$ only for a narrow range of permeabilities.

The following overall conclusion on the effect of $k$ on the convective flux of soil gas can be deduced from Eqs. 13, through 19:

(1) For transient flow, $v=f\left(k^{0.5}\right)$; for steady-state flow $v=f(k)$. 
(2) At $t=\infty$, and $z=0, v\left(p_{0}, t\right)$ is a minimum. Thus the steady-state flow velocity is a lower bound at the point where the initial pressure drop occurs.

These conclusions must be considered when the correlation between permeability and the rate of radon entry into houses is assessed.

\section{VARIABLES AND THEIR MEASUREMENT}

\subsection{Radon Generation in Soil Pores}

The rate of radon generation in the pore space can be measured by the quantity $C_{\max }[E q(4)]$. The variables on which $C_{\max }$ depends are $A_{R a}$, the radium activity concentration in the soil grains, $\gamma_{d}$, the dry density of the soil, and $f$, the emanation coefficient. These variables are subsequently discussed.

\section{Radiun Activity Concentration}

The quantity $A_{R a}$ is a measure of the radium content of the soil. Radium ( $\operatorname{Ra}^{226}$ ) has a half-life of 1600 years. Thus, for the time frame of the problem considered the radium activity concentration is an invariable quantity.

A considerable amount of data on radium activity concentrations for various soils is available [i.e. Nazaroff et a., 1988, DSMA Atcon, 1983]. The data suggest that the radium activity concentration in surface soils ranges typically from 10 to $100 \mathrm{~Bq} \cdot \mathrm{kg}^{-1}$. However, values in excess of $1,700 \mathrm{~Bq} \cdot \mathrm{Kg}^{-1}$ have been recorded for uranium rich soils. A range of values from 0.4 to $3,500 \mathrm{~Bq} \cdot \mathrm{kg}^{-1}$ were recorded for rocks. Values tend to be high for shales and schists [Gundersen et al., 1988] and tend to decrease with silica content in igneous rocks [Nazaroffet al., 1988].

The $\mathrm{Ra}^{226}$ activity concentration can be measured in the laboratory by determining the $\mathrm{Bi}^{214}$ emission of samples which have been stored long enough for the $\mathrm{Bi}^{214}$ to come into equilibrium with its radium precursor. Gamma spectroscopy is used to make the measurement. 
More rapid but less accurate measurements can be performed in the field. Measurements of radium activity concentration at a shallow depth (less than 0.5 m) can be made by detectors suspended above the ground surface. There are two problems affecting the accuracy of these measurements: (1) The measured emission decreases with increasing moisture contents. This error could be corrected by determining moisture contents. (2) Radium concentrations are inferred from $\mathrm{Bi}^{214}$ measurements. However radium decays directly to radon gas, which in turn decays to Po ${ }^{218}$, a metal which rapidly attaches itself to a nearby surface where it decays to $\mathrm{Bi}^{214}$. Near the soil surface, part of the radon gas escapes to the atmosphere. Thus, near the surface, a measurement of $\mathrm{Bi}^{214}$ is likely to underestimate the radium concentration by approximately $20 \%$. This is another error which needs to be compensated for, probably by estimating the effect. Measurements at greater depth can be made by borehole probes which have been developed for uranium detection.

Gamma ray spectroscopy is carried out either by sodium iodide (NaI) scintillating detectors or by solid-state diode detectors which are usually made of germanium (Ge). The $\mathrm{NaI}$ detector measurements have lower resolution than the Ge detector measurements, but NaI detectors operate at ambient temperatures and are less expensive than the Ge detectors. Ge detectors operate at cryogenic temperatures. While the precision of the $\mathrm{Ge}$ detector measurements is much greater than that of the NaI measurements, the overall measurement accuracy is not necessarily much improved because of the previously discussed uncertainties associated with insitu measurements.

\section{Dry Density of Soils}

Dry densities of soils which are of interest in this study range from 1,200 $\mathrm{kg} \cdot \mathrm{m}^{-3}$ for loose micaceous sand to $2,300 \mathrm{~kg} \cdot \mathrm{m}^{-3}$ for silty sands with gravels (mostly glacial tills). Data on various soil types are given in Tables $1 a$ and $b$. The data tabulated were developed from different information bases. The $95 \%$ modified proctor densities are for ASTM D1557 which represents compaction greater than that normally used by the building construction industry (ASTM D698) and should be considered an upper bound for compacted soils. The dry density of the soil in situ can be considered an invariable quantity, even 
TABLE 1a: Typical Soil Properties

(After Lambe and Whitman, 1969)

\begin{tabular}{|c|c|c|c|c|c|c|}
\hline \multirow[b]{2}{*}{ Soil Type } & \multicolumn{2}{|c|}{ Void Ratio } & \multicolumn{2}{|c|}{ Porosity } & \multicolumn{2}{|c|}{ Dry Density $\mathrm{kg} \cdot \mathrm{m}^{-3}$} \\
\hline & $e_{\max }$ & $e_{\min }$ & $\mathrm{n}_{\max }$ & $\mathrm{n}_{\mathrm{min}}$ & $\gamma_{\text {dmin }}$ & $\gamma_{\text {dmax }}$ \\
\hline Uniform Spheres & 0.92 & 0.35 & 0.476 & 0.26 & & \\
\hline Standard Ottawa Sand & 0.80 & 0.50 & 0.44 & 0.33 & 1,470 & 1,760 \\
\hline Clean Uniform Sand & 1.00 & 0.40 & 0.50 & 0.29 & 1,330 & 1,890 \\
\hline Uniform Inorganic silt & 1.10 & 0.40 & 0.52 & 0.29 & 1,280 & 1,890 \\
\hline Silty Sand & 0.90 & 0.30 & 0.47 & 0.23 & 1,390 & 2,030 \\
\hline Fine to Coarse Sand & 0.95 & 0.20 & 0.49 & 0.17 & 1,360 & 2,210 \\
\hline Micaceous Sand & 1.20 & 0.40 & 0.55 & 0.29 & 1,220 & 1,920 \\
\hline Silty Sand and Gravel & 0.85 & 0.14 & 0.46 & 0.12 & 1,430 & 2,340 \\
\hline
\end{tabular}

TABLE 1b: Typical Dry Densities of Soils

(After Holtz and Kovacs, 1981)

\begin{tabular}{|c|c|c|}
\hline \multirow[b]{2}{*}{ Soil Type } & \multicolumn{2}{|c|}{ Dry Density, $\mathrm{kg} \cdot \mathrm{m}^{-3}$} \\
\hline & $\gamma_{\mathrm{dmin}}$ & $\gamma_{\text {dmax }}$ \\
\hline Sands and Gravels & 1,500 & 2,300 \\
\hline Silts and Clays & 600 & 1,800 \\
\hline Glacial Tills & 1,700 & 2,300 \\
\hline Crushed Rock & 1,500 & 2,000 \\
\hline Peats & 100 & 300 \\
\hline Organic Silts and Clays & 500 & 1,500 \\
\hline
\end{tabular}

Typical Values for 958 Modified Proctor Density: (after Holtz and Kovacs, 1981)

Clean Uniform Sand (fine to medium)

Well Graded Silty Sand

Well Graded Clean Fine to Course Sand
$1,770 \mathrm{~kg} \cdot \mathrm{m}^{-3}$

1,880 "

$2,030 \quad "$ 
though minor changes may occur as a result of applied surface loads. However if the soil is excavated and subsequently replaced as fill the density is likely to change. Granular soils (gravels, sands and silts) compacted in accordance with prevailing standards are likely to have densities greater than their original in situ density. However finegrained soils (silty clays and clays) and some glacial tills may have densities which are smaller than the original in situ density.

Several methods are used to measure dry density. For cohesive (fine grained) soils which are not desiccated, in situ density as well as water content can be determined in the laboratory from undisturbed samples, usually taken by pressing a thin wall tube into the soil. However undisturbed samples are difficult to take in granular soils, particularly sands and gravels, and in dry cohesive soils, and density determinations from disturbed samples (such as split spoon samples taken in the Standard Penetration Test (SPT) [ASTM D1586] are likely to be inaccurate. Soil density can be measured insitu by removing a known volume of soil and determining its dry weight in the laboratory [ASTM D1556]. This method is somewhat cumbersome and can only be performed on the soil surface or on the bottom of a test pit large enough for a person to enter, but it is commonly used in compaction control. Nuclear density tests [ASTM D2922] are more rapid and less cumbersome than the ASTM D1556 method. The nuclear method also usually combines density and moisture content measurements (the methods described are used for compaction control where it is also important to determine moisture content). Density is measured by $\gamma$-radiation scatter, using radium or a radioactive isotope of cesium as a source. Moisture content is measured by neutron scatter caused by hydrogen atoms. Typically americiumberyllium isotopes are used as neutron source. Like ASTM D1556, the nuclear density test described above is used for compaction control and is performed on the soil surface. However, nuclear borehole probes have been built [i.e. Vaswani, 1975]. .

It should be noted that in view of the uncertainties associated with estimates and measurements of the variables associated with the radon generation and transport problem, great accuracy in the measurement of the dry density of the soil may not be necessary (however, as will be discussed later, accuracy in the 
determination of the moisture content is important). A reasonably good estimate can be made with the aide of Table 1, a definition of the soil type, and some information from penetration tests, such as the SPT, the cone penetration test (CPT) [ASTM D3441) or the helical probe test (HPT) [Yokel and Mayne, 1986). The dry density of man-made fill material can also be estimated on the basis of information on the procedure used to place the fill, or from field density tests performed during the placement of the fill.

\section{Emanation Coefficient ( $f$ )}

While the radium content and the dry density of the soils can be considered invariable quantities for practical purposes, the emanation coefficient, and thus also the quantity $C_{\max }$, strongly depends on the moisture content of the soil. The mechanism by which radon atoms are emitted to the pore space is discussed by Nazaroff et al., 1988 and Tanner, 1964 and 1980. Since linear momentum is conserved, $\mathrm{Rn}^{22}$ atoms, when created by the $\alpha$ decay of radium, posses a kinetic energy of $86 \mathrm{keV}$. The atoms travel from their site of generation until their energy is transferred to the host material for an average distance which depends on the density of the host material. This distance would be 0.02-0.07 $\mu \mathrm{m}$ in common minerals, $0.1 \mu \mathrm{m}$ in water, and $63 \mu \mathrm{m}$ in air. Thus on the average the distance at which the path of the radon atom terminates in the soil gas is 630 times greater than the average travel distance in water, and in many instances exceeds the travel distance available in the pore space. Thus when the pore space is filled with gas, many of the radon atoms emitted traverse the pore space and embed themselves in soil grains. Only a relatively small portion of the radon atoms either terminate in the pore space or return to the pore space by diffusion. If the pores are filled with water, a much larger portion of the radon atoms emitted remains in the pore space.

Attempts have been made to model this problem mathematically, considering the three components of the emanation coefficient, direct recoil, indirect recoil and diffusion, and assuming spherical intact soil grains. Interestingly, it was found that the mathematical model yields much smaller emanation coefficients than those measured in the laboratory [Nazaroff et al., 1988, Tanner, 1980]. The reasons advanced for the discrepancy are: (1) that the radium, rather than being 
distributed uniformly in the mass of the soil grains is concentrated in secondary crusts near the grain surface; and (2) that the crystalline structure in the vicinity of newly formed radon atoms is damaged by chemical corrosion and radiation, permitting the atoms to more readily migrate into the pore space than the density of the soil grains would otherwise indicate. Some confirmation for these hypotheses is provided by measurement of emanation coefficients in the Island of Hawaii (Wilkening, 1974). Emanation coefficients measured on samples from lava fields of recent geological origin were on the order of 0.02 , while those from thin organic soils were on the order of 0.55 and those from deep agricultural soils 0.7 .

Figure 1 (taken from Nazaroff et al., 1988) shows a correlation curve between emanation coefficients and moisture content developed by Strong and Levins, 1982 for a sample of uranium mill tailings. The curve indicates that the emanation coefficient for a dry sample was approximately 22 of that for a saturated sample. Initially the emanation coefficient increased rapidly with the moisture content until the moisture content reached approximately $25 \%$ of saturation, at which point the coefficient is $80 \%$ of that measured at saturation. Some additional data are tabulated by Nazaroff et al., 1988, p 74. DSM Atcon, 1983 tabulated data derived from measurements on oven-dried samples (Table 4). They conclude that typically values of $f$ for oven-dried soils are 0.15 to 0.20 and recommend to assume $f$ values for moist soils to be "virtually constant" at 0.35. Unfortunately there is only a very limited data base to justify this suggestion. For instance Greiner, 1985 measured the effect of moisture content on the emanation coefficient from ground coal and concluded that the emanation coefficient for a dry sample was very low.

The emanation coefficient can be measured on soil samples which were sealed for long enough for $C$ to reach $C_{\max }$ in the pore space, at least 14 days (3.7 half lives). A gas volume can then be withdrawn and expanded into a Lucas flask to measure the radon concentration. An efficient measurement method for $C_{\max }$ for saturated conditions using very small soil samples and liquid scintillation was described by Wadach and Hess, 1985. Both, $f$ for dry and for saturated conditions are invariant quantities, however the emanation coefficient in the field at any point in time depends on the moisture content of the soil. The 


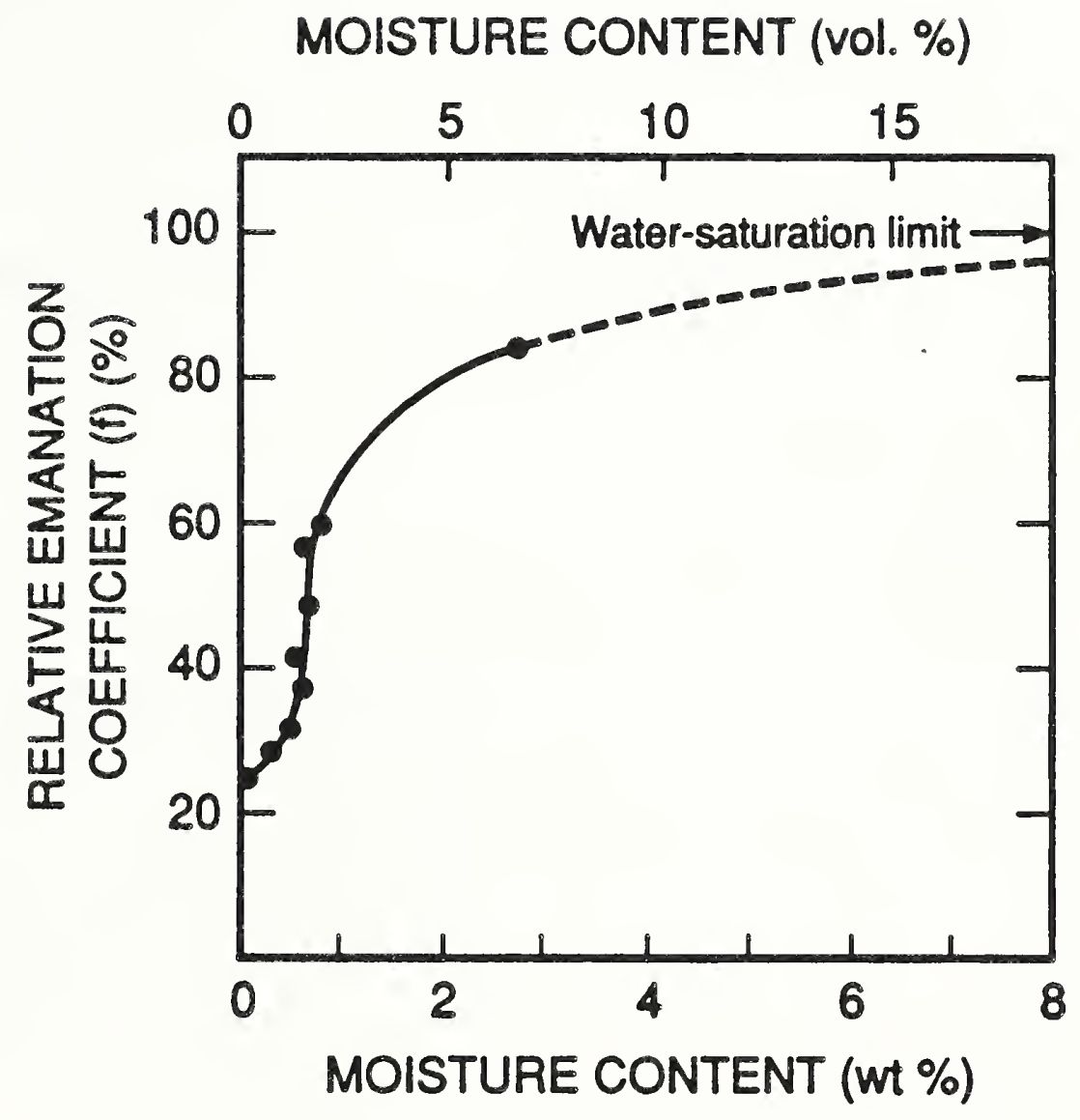

Figure 1: Effect of Moisture Content on the Emanation Coefficient for a sample of Uranium Mill Tailings (from Strong and Levins, 1982). 
emanation coefficient for the dry condition is a lower limit. The maximum radon flux in the field would occur in a moist condition, when there is enough moisture content to substantially increase the radon generation over that in a dry condition but not enough moisture to substantially reduce the gas permeability of the soil. The moisture content associated with this condition depends on the particle size distribution in the soil and falls somewhere between the field capacity, where the capillary component of the pore water (pore water which is retained by surface tension and does not drain by gravity forces) is retained and the wilting point, where only the hygroscopic component of the pore water remains in the pores (electrostatically adsorbed pore water which is retained for a long period of time in otherwise dry soil). The approximate moisture contents associated with these conditions are given in Table 2 [after Nazaroff et al., 1988]. Except in arid regions, the hygroscopic water is retained most of the time. However according to Nazaroff et al., 1988, this portion of the pore water does not significantly increase the emanation coefficient. In most soils the capillary water is retained at some height above the groundwater table.

TABLE 2: Typical Water Retention Characteristics of Soils (taken from Nazaroff et al., 1988)

\begin{tabular}{|c|c|c|c|c|}
\hline Soil Type & Grain Size & Porosity & \multicolumn{2}{|c|}{ Saturation (percent) } \\
\cline { 4 - 5 } & $\mathrm{mm}$ & & Field Cap. & Wilting Pt. \\
\hline Sand & $2.00-0.06$ & 0.4 & 15 & 5 \\
Silt & $0.06-0.002$ & 0.5 & 58 & 10 \\
Clay & $<0.002$ & 0.6 & 68 & 48 \\
\hline
\end{tabular}

\subsection{Radon Transport in Soils}

The variables controlling the radon flux are the diffusion coefficient and the gas permeability coefficient. For convenience, the formulations in this report deal with bulk, rather than effective coefficients. Thus while the actual radon flux takes place within the part of any cross section area which is occupied by the pores, the bulk coefficients are averaged over the entire cross section area. The diffusion and permeability coefficients are subsequently discussed. 


\section{Diffusion Coefficient}

While radon exhalation from the exposed soil surface to the atmosphere is to a large extent the result of diffusion, the dominant transport mechanism associated with the entry of radon into buildings is convection, unless the gas permeability coefficient is very low, a situation which is usually associated with low radon entry rates. Since the diffusion coefficient varies primarily with moisture content, but does not vary much with soil type, it is not recommended in this report to measure the diffusion coefficient. For practical purposes it is considered adequate to use $E_{q}(9)$ for estimating the effective diffusion coefficient. To obtain the bulk diffusion coefficient the results of Eq(9) must be multiplied by $n$. An upper bound for the effective diffusion coefficient is the diffusion coefficient of radon in open air, $D_{0}$, which is $1.2 \cdot 10^{-5} \mathrm{~m}^{2} \cdot \mathrm{s}^{-1}$. A lower bound in saturated soil is $2 \cdot 10^{-10} \mathrm{~m}^{2} \cdot \mathrm{s}^{-1}$. Note that as a result of diffusion the radon concentration near the soil surface is less than that at greater depths. In an ideal radon concentration profile where $\mathrm{C}=0$ at the soil surface and $C=C_{\max }$ at an infinite depth $C$ would be $0.63 C_{\max }$ at the depth of $1 \ell$ which is approximately $1 \mathrm{~m}$.

\section{Permeability Coefficient}

The permeability coefficient is a measure of the frictional resistance to the flow of soil gas in the pores. It depends on the shape and size of the pores. Since in most soils the pores are at least partially filled with water, the gas permeability is strongly dependent on the moisture content of the soil. The gas permeability of dry soils and the water permeability of saturated soils can be considered invariant.

Since in the mathematical formulations previously presented the soil was assumed isotropic with respect to permeability, $\mathrm{k}$ could be treated as a scalar quantity. However, because of the manner in which soils in nature (and also during construction) are deposited and pre-consolidated, the horizontal permeability is in many instances greater than the vertical permeability. The ratio between the horizontal and vertical permeabilities ranges from about three for soils which are pre-consolidated but not stratified to more than an order of magnitude and 
sometimes two orders of magnitude for stratified sedimentary soils such as varved clays. In some residual soils, which formed by the decomposition of the local rock formation rather than by deposition of particles transported from other locations and which were not heavily pre-consolidated during their geological history, the vertical permeability exceeds the horizontal permeability. Note that the northern part of the United States was glaciated during its recent geological history and that therefore most soils in these regions were pre consolidated by thick sheets of ice.

A considerable amount of data is available for saturated water permeability from field and laboratory tests. These data can be used to approximately estimate dry gas permeability. However, it is important to recognize that for flow of water through soils the boundary velocity at the surface of the soil grains is zero, whereas for gases it is not zero [Corey, 1988, p.98]. This phenomenon was first observed by Klinkenberg, 1941, and is referred to as the "Klinkenberg effect" or slipflow. The value of $\mathrm{k}$ derived from water permeability is a lower bound which is approached by gas flows at very large pressures. At atmospheric pressures, the gas permeability will be approximately equal to the water permeability for coarse sands. It could be as large as twice the water permeability for particle sizes in the silt range [Corey, 1988]. In view of the fact that permeabilities range over several orders of magnitude and that for finegrained soils the radon flux is primarily attributable to diffusion or convection through fissures, the increase in permeability attributable to the Klinkenberg effect is not very significant. Nevertheless, gas permeabilities derived from data on water permeability should be considered lower bound values.

Since Darcy's coefficient for water permeability is given for the gradient of the water head and has the dimension of $\mathrm{L} \cdot \mathrm{T}^{-1}$ (velocity), it can be converted to $\mathrm{k}$ as follows:

$$
\mathrm{v}=\mathrm{k}_{\mathrm{w}} \frac{\mathrm{dH}}{\mathrm{d} \ell} \leq \frac{\mathrm{k} \gamma_{\mathrm{w}}}{\mu_{\mathrm{w}}} \frac{\mathrm{dH}}{\mathrm{d} l} ; \quad \therefore \mathrm{k} \geq \mathrm{k}_{\mathrm{w}} \frac{\mu_{\mathrm{w}}}{\gamma_{\mathrm{w}}} ;
$$

where $\gamma_{w}, \mu_{w}$ and $k_{w}$ are the unit weight, dynamic viscosity and permeability coefficient of water.

(a) $18^{\circ} \mathrm{C}: \mu_{w}=1.053 \cdot 10^{-3} \mathrm{~Pa} \cdot \mathrm{s}$ and $\gamma_{w}=9.8 \cdot 10^{3} \mathrm{~N} \cdot \mathrm{m}^{-3}$

therefore: $\mathrm{k}\left(\mathrm{m}^{2}\right) \geq \mathrm{k}_{\mathrm{w}}\left(\mathrm{m} \cdot \mathrm{s}^{-1}\right) \cdot 1.07 \cdot 10^{-7}(\mathrm{~m} \cdot \mathrm{s}) \quad \ldots(20)$ 
Some data derived from information on water permeability are given in Table 3 which describes soil characteristics and some methods of determining water permeability. The data were originally presented by Casagrande and Fadum, 1944. The laboratory methods listed are constant head permeameter, falling head permeameter, horizontal capillarity test and consolidation test (Lambe, 1958). Most of the laboratory tests can be used to determine the water permeability of saturated samples (though in some instances it may be difficult to drive all the soil gas from the pore space). However the horizontal capillarity test measures the permeability of the capillary portion of the pore space (at approximately $80 \%$ saturation) which is approximately 33 to $50 \%$ of the saturated permeability [Lambe, 1958]. The permeability of the pores larger than those in the capillaxy. range would be the difference between the permeability at saturation and the permeability obtained in the horizontal capillarity test. This value is of interest, because the emanation coefficient of partially saturated soils is much higher than that of dry soils and the degree of saturation in the horizontal permeability test may be similar to that below basement foundations which are close to the phreatic surface, where the soil is partially saturated as a result of capillary suction.

The only field permeability test listed in Table 3 is the pumping test, which can only be conducted below the groundwater table. While this latter test is not practical for the purpose site classification for radon, it provided a large volume of reliable empirical permeability data. Many other types of in situ water permeability tests, mostly borehole tests have been developed. An overview and assessment of available test methods is provided by Milligan, 1975. The permeability of soils can also be measured electrically and characterized by a "formation factor" which is the ratio of the conductivity of the electrolyte occupying the pore space of a saturated soil sample to the conductivity of the soil-solution mix. This measurement can be performed in situ and can also be used to determine anisotropy. The problem with this measurement is that the soil must be saturated [Arulmoli et al., 1985]. 
Table 3. Soil Permeability and Drainage Characteristics (based on data presented by Holtz and Kovacs, 1981, Peck et al., 1974) $\begin{array}{lllllllllllll}\log k\left(\mathrm{~m}^{2}\right) & -7 & -8 & -9 & -10 & -11 & -12 & -13 & -14 & -15 & -16 & -17 & -18\end{array}$

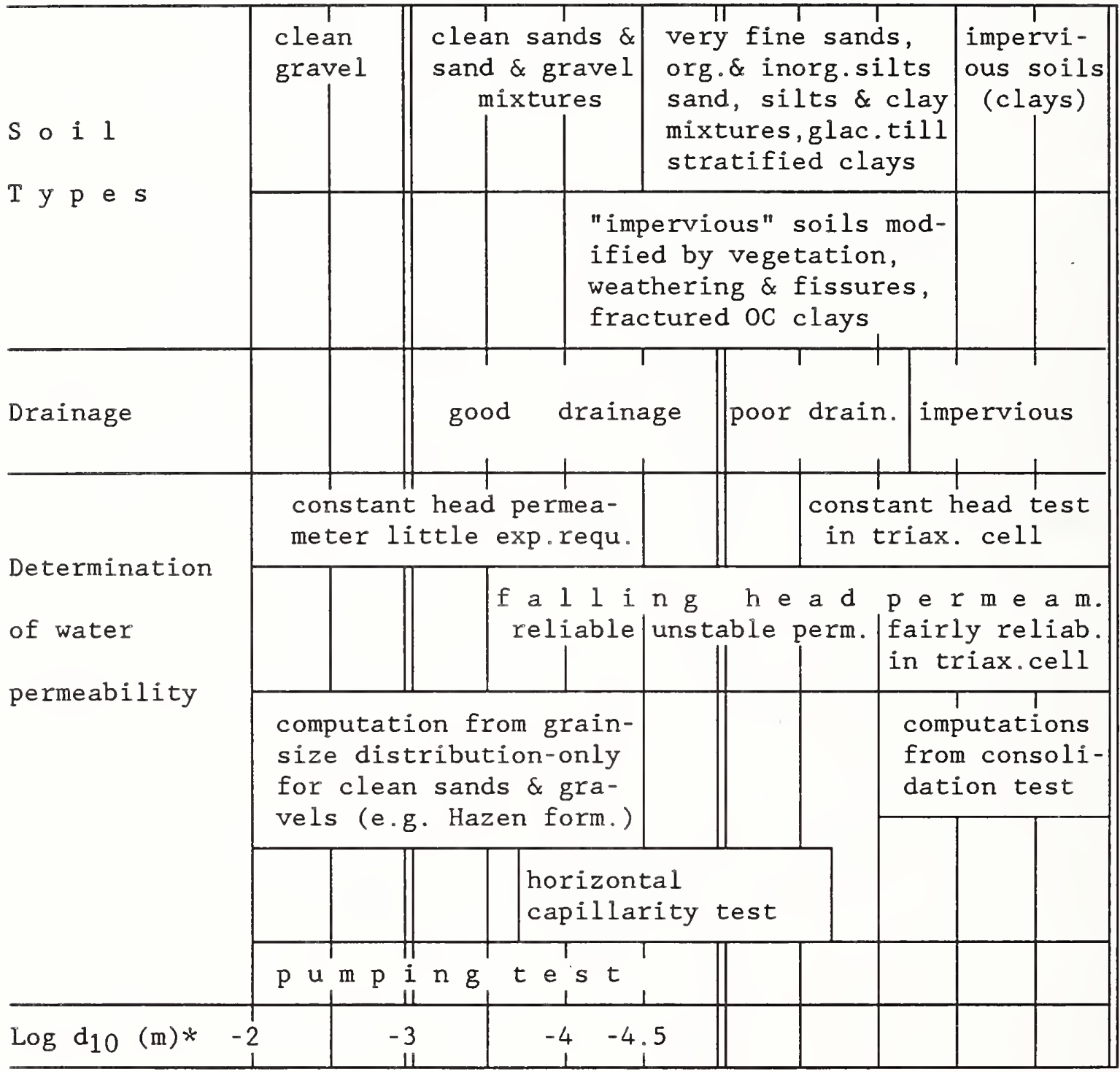

* Particle sizes calculated by Hazen formula 
A test of considerable practical interest is a percolation test developed by the Federal Housing administration (FHA) for the purpose of designing subsurface wastewater absorption fields [HUD Minimum Property Standards, 1973]. The test is required by most jurisdictions in areas not served by municipal sewage disposal systems. It is performed in an open auger hole or pit. The percolation rate is measured over a four-hour period after the soil was saturated for a specified period of time. While there are presently no data correlating percolation rate with water permeability, such data can be generated. Considerable economy could be realized by utilizing these test results for radon risk evaluation.

The gas permeability values listed in Table 3 were converted from water permeability using Eq (20) and therefore represent lower-bound values. The vertical double lines represent divisions between easily recognizable soil categories (gravels; sands; silts and clays) and are considered "benchmark" values.

Of particular interest are the modified "impervious" soils. The permeability of these soils cannot be correlated with their grain size distribution, because their permeability is caused by structural defects and exceeds their intact permeability by up to several orders of magnitude. The range of values given in Table 3 extends over four orders of magnitude and is derived from empirical data. The most common causes of structural defects are cycles of swelling and shrinkage, shrinkage caused by desiccation, and effects of vegetation. In the first category are the swelling clays in semi-arid regions in the U.S. These soil deposits shrink and swell seasonally and develop fissures in the dry season. As a result of the cyclic volume changes these soils are overconsolidated and develop structural defects when lateral confinement is removed by excavation. Desiccated clays may be fissured before construction starts. In other instances clay deposits may have a high enough natural moisture content to prevent shrinkage cracking, but will eventually desiccate when covered by building foundations. Vegetation effects are of particular interest in slab-on-grade buildings which rest on very shallow soil deposits. 
Shrinkage cracking occurs locally when the capillary pressures exceed the tensile strength (cohesion) of the soil. The propensity of clays for developing these structural defects is related to measurable index properties. Soils identified in the Table 4 as having a high or very high degree of expansion should be considered susceptible to shrinkage cracking. Note that the Atterberg limits alone can provide the necessary information.

\section{Table 4: Estimate of Expansion from Classification Tests}

(After U.S. Bureau of Reclamation, 1974)

\begin{tabular}{l|l|l|l|l}
$\begin{array}{l}\text { Degree of } \\
\text { Expansion }\end{array}$ & $\begin{array}{l}\text { Probable Exp. } \\
\text { of volume) dry } \\
\text { to saturated } *\end{array}$ & $\begin{array}{l}\text { Colloidal } \\
\text { Content } \\
(8-1 \mu \mathrm{m})\end{array}$ & $\begin{array}{l}\text { Plasticity } \\
\text { Index (PI)** }\end{array}$ & $\begin{array}{l}\text { Shrinkage } \\
\text { Limit (SL)** }\end{array}$ \\
\hline Very High & $>30 \%$ & $>28 \%$ & $>35$ & $<11$ \\
High & $20-30 \%$ & $20-318$ & $25-41$ & $7-12$ \\
Medium & $10-20 \%$ & $13-23 \%$ & $15-28$ & $10-16$ \\
Low & $<10 \%$ & $<15 \%$ & $<18$ & $>15$ \\
\hline
\end{tabular}

* Expansion is under a surcharge of $6.89 \mathrm{~Pa}$ (1 psi)

$* *$ Atterberg Limits according to ASTM D4318

A simple test that could be used to identify fissured clays is the "drying test" [Yokel and Tucker, 1980]. A small clay sample is allowed to dry and its dry strength and integrity is examined manually.

The permeability caused by structural defects in soils can be measured in particular instances, but cannot be quantified in terms of other measurable soil index properties. However clays susceptible to shrinkage cracking can be identified by their swelling potential. Studies of this problem have been conducted by Herzog and Morse, 1984, Long et al. 1982, Mckinley et al. 1978, Snow, 1969, and Bosscher et al. 1988.

Gas permeability can be measured by in situ tests. Methods have been developed to combine these tests with measurements of radon concentrations in the soil gas 


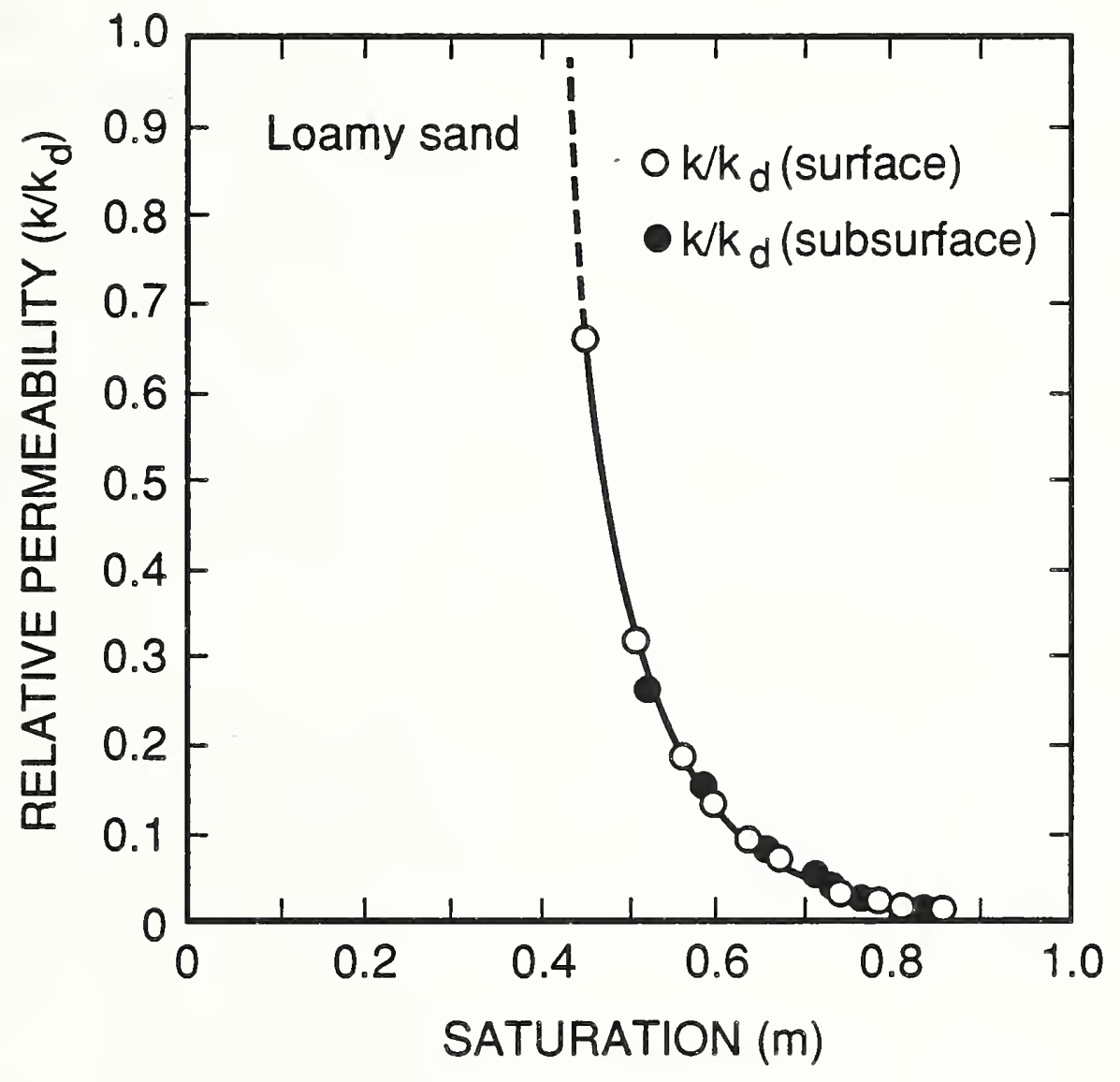

Figure 2: Relative Air Permeability of a Loamy Sand (from Nazaroff and Nero, 1988) 
[Tanner, 1987, Kunz, 1988, Sextro, 1988, Surback and Piller, 1988]. While these measurements provide valuable information, they are sensitive to the moisture content at the time of measurement. Figure 2, which was taken from Nazaroff et al., 1988 shows correlations between moisture content and gas permeability for a loamy sand (silty sand). It can be seen that for this soil a large correction would be required for saturations in excess of 55\%, and that for smaller saturations the permeability is very sensitive to the moisture content.

Typical values for gas permeability presented by Nazaroff et al., 1988 are shown in Table 5. The information in the table is in part derived from the same sources as that in Table 3 and thus is compatible with Table 3 . Some mathematical models were developed which correlate particle size distribution with permeability (refer to Nazaroff et al., 1988, 61-65, Leonards, 1962, 119124). Two models are discussed because they can be used for site characterization. Hazen, 1892, derived an empirical formula on the basis of data for sharp, uniform sands used for filters. His classical formula considered particle size and had a correction for the temperature effects on viscosity. The following expression can be derived from Hazen's formula:

$$
\mathrm{k}=\mathrm{cd}_{10}{ }^{2}
$$

where: $\quad c=$ a coefficient accounting for density

$\mathrm{d}_{10}=$ the particle size which is equal or larger than $10 \%$ of the particles by weight, also called the "effective" particle size.

Hazen found that his formula is valid for sands whose uniformity coefficient: $C_{u} \leq 5$, where $\quad C_{u}=\frac{d_{60}}{d_{10}}=$ the uniformity coefficient which is a measure of grain size variation. Hazen observed that the highest value of $c$ was approximately twice the lowest value. For gas permeability, the Hazen equation can be written as:

$$
\mathrm{k}\left(\mathrm{m}^{2}\right) \simeq(0.7 \text { to } 1.4) \cdot 10^{-3} \mathrm{~d}_{10}{ }^{2} \text { where } \mathrm{d} \text { is in } \mathrm{m} \ldots(22)
$$

A good average value for the bracketed term in Eq(22) is 1. In present engineering practice a range of values from 1 to 1.5 is often suggested [Peck et al., 1973], rather than the range in Eq(22) which was originally determined by Hazen. It was suggested that the Hazen formula gives only an indication of the order of magnitude of permeability [Sowers and Sowers, 1970] and its validity 
Table 5: Typical Gas Permeability Values

(From Nazaroff et al., 1988)

Log $k\left(m^{2}\right)$

\begin{tabular}{l|l|l|} 
C l e a n gra ve 1 & \\
& -8 \\
\hline
\end{tabular}

$\mid \begin{array}{ll}-7 \\ -1\end{array}$

C l e a n s a nds,

$\mathrm{C} l$ e a n $\mathrm{s}$ a $\mathrm{nd}$ a $\mathrm{nd}$

g r a vel mix t u re

Very fine sands,

Organic and inorganic

silts,

Mixtures of sand, silts

and clay, etc.

$-11-$ Clean well graded sand \& gravel

- Uniform fine sand

$-12$

and clay, etc.

Homogeneous clays 
was thought to be limited to loose clean uniform sand (with less than 5\% of particles passing the \#200 sieve) [Leonards, 1962, Holtz and Kovacs, 1981 ]. However, data presented by Milligan, 1976, p.13 and Fig.6 indicate very good agreement between the Hazen formula and high quality laboratory and pumping test data, even for uniformity coefficients as high as 20. As Table 3 indicates, the Hazen equation applies in the range of $\mathrm{k} \geq 10^{-12} \mathrm{~m}^{2}$ which is the range of permeabilities where convective flow tends to dominate radon transport.

The Hazen formula does not have a density term (even though density effects are implicit in the variation of the coefficient $c$ ). Taylor, 1948, suggested the following correlation between the void ratio $e=n /(1-n)$ and the permeability:

$$
\frac{k_{1}}{k_{2}}=\frac{C_{1} e_{1}{ }^{3}}{1+e_{1}}: \frac{C_{2} e_{2}{ }^{3}}{1+e_{2}}
$$

For sands $C_{1} \simeq C_{2}$. Thus the two coefficients can be factored out of the equation. A simpler relationship is frequently used [Sowers and Sowers, 1970]:

$$
\mathrm{k} \propto \mathrm{e}^{2}=[\mathrm{n} /(1-\mathrm{n})]^{2}
$$

A more sophisticated mathematical model for $k$ was presented by Rogers and Nielson, 1988:

$k=n \cdot(1+n) \cdot\left(\frac{d}{3}\right)^{2} \cdot \exp \left(-1.4 m-2 m^{2}\right) \cdot\left\{0.0034 \cdot \exp \left[0.264 \cdot s^{1.33}-0.6 m \cdot(1-0.1 S)\right]\right\} \ldots$

where: $\quad m$ = moisture saturation (as a fraction of full saturation)

$\mathrm{d}=$ geometric mean particle diameter (by size)

$S=$ geometric standard deviation of particle diameter distribution

The equation assumes a log-normal particle size distribution (by diameter). This is a realistic assumption for many natural granular materials. The first half of $\mathrm{Eq}(25)$ is for a geometric standard deviation of 10 , and the second half of the equation (inside the braces) adjusts the calculated values for other geometric standard deviations. An interesting aspect of $E q(25)$ is that $d_{10}$ represents a close approximation to the geometric mean particle diameter, and $C_{u}$ is approximately the geometric standard deviation. On this basis a comparison is made between Eqs. (22) and (25), using $\mathrm{s}=3$ and $5, \mathrm{n}=0.5$ and $\mathrm{m}=0$. The equation is dimensionally consistent. Thus, if $\mathrm{d}$ is in $\mathrm{m}, \mathrm{k}$ is in $\mathrm{m}^{2}$. 


\begin{tabular}{l|l|l|l}
$\mathrm{d}_{10}(\mathrm{~m})$ & $\mathrm{k}\left(\mathrm{m}^{2}\right)[\mathrm{Eq}(22)]$ & \multicolumn{2}{|c}{$\mathrm{k}\left(\mathrm{m}^{2}\right)[\mathrm{Eq}(25)]$} \\
\hline \multirow{2}{*}{$10^{-2}$} & $10^{-7}$ & $\mathrm{~S}=5$ & $\mathrm{~S}=3$ \\
\cline { 2 - 3 } $10^{-3}$ & $10^{-9}$ & $2.7 \cdot 10^{-7}$ & $8.8 \cdot 10^{-8}$ \\
$10^{-4}$ & $10^{-11}$ & $2.7 \cdot 10^{-9}$ & $8.8 \cdot 10^{-10}$ \\
$10^{-4.5}$ & $10^{-12}$ & $3.5 \cdot 10^{-11}$ & $8.8 \cdot 10^{-12}$ \\
\hline
\end{tabular}

It can be seen that the calculated permeabilities are in the same range, even though the value calculated by $E q(25)$ for $S=5$ is higher than the upper limit suggested for Eq (20). This is encouraging, since Eq(25) was derived from an entirely different data base than that used for Eq(22). Eq(25) requires consideration of porosity and moisture content.

The term for moisture content in $\mathrm{Eq}(25)$ is of interest because it could potentially be used to correct field measurements of gas permeability for the moisture content at the time of the measurement. Eq(25) can be rewritten as: $k=0.0034 n(1+n)\left(\frac{d}{3}\right)^{2} \cdot \exp \left(0.264 \cdot s^{1.33}\right)\left(\exp \left[-1.4 m-2 m^{5}-0.6 m(1-0.1 s)\right]\right\} \quad \ldots(26)$ The term inside the braces in Eq(26) is a correction for the moisture effect. Discussions with the authors of $\operatorname{Re}[$ [45] indicate that the moisture term is based on a limited amount of laboratory data for soils ranging from sands to clays, together with an analytical model for gas permeability. Moisture content effects calculated from $\mathrm{Eq}(26)$ are plotted in figure 3, together with the data from figure 2 and a typical curve shown by Corey, 1988. The data from figure 2 and Corey's curve are not inconsistent, because Corey's curve, which is a plot of Eq 3.34,i in Corey, 1988, depends on the "residual saturation" and on an exponential coefficient which are soil-specific (the data in figure 2 are associated with a higher residual moisture content than Corey's curve shown in Figure 3). Figure 3 indicates that Eq (24) does not provide a realistic correction factor for the effect of saturation. More data are needed to develop correction factors for moisture content which can be correlated with readily measurable soil index properties. 


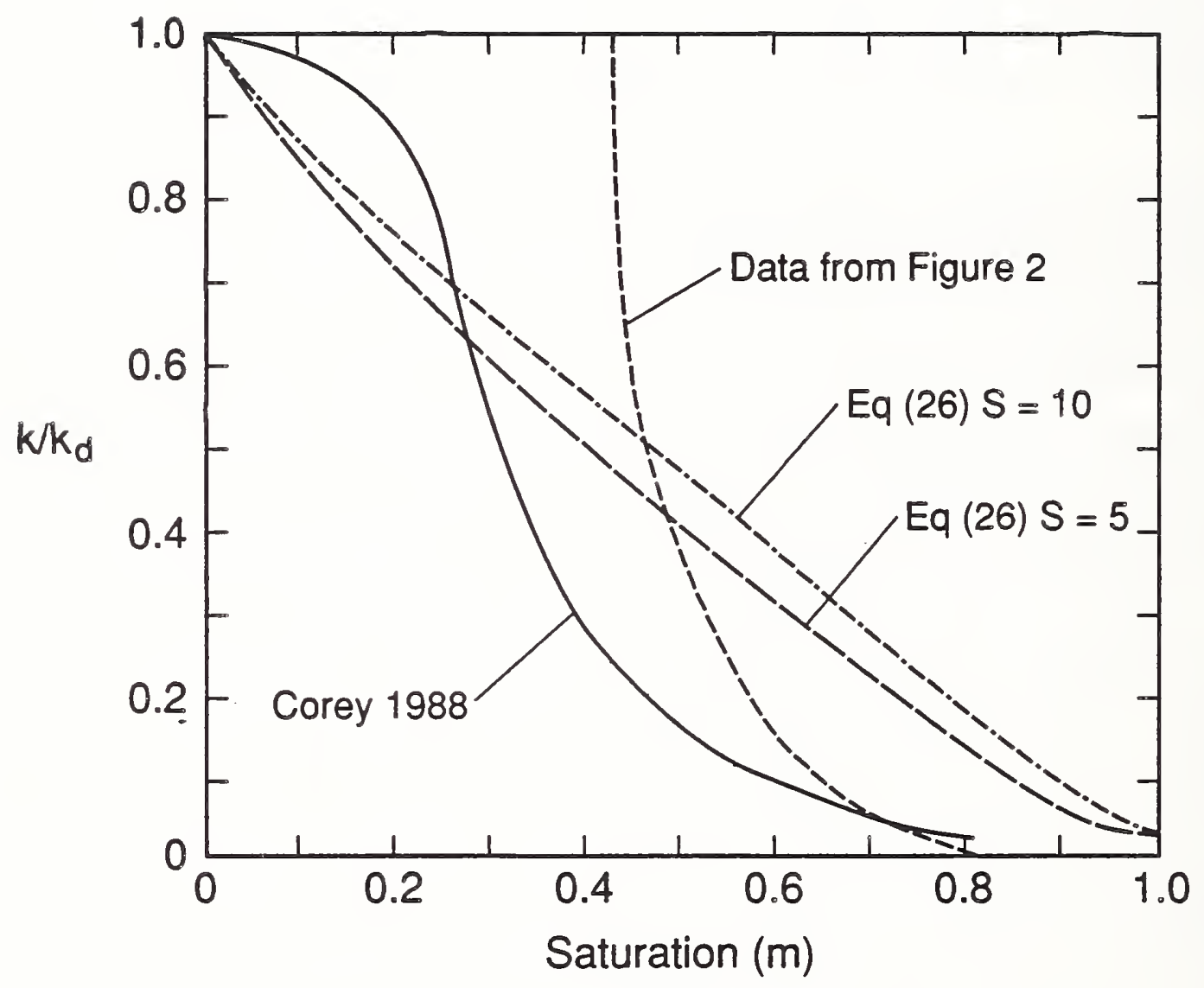

Figure 3: Comparison of data and predictions of the effect of the degree of saturation on the gas permeability of soils. 


\subsection{Summary}

The radium activity concentration can be measured in the laboratory or in the field using $\gamma$-spectroscopy. It varies typically from 10 to $100 \mathrm{~Bq} \cdot \mathrm{kg}^{-1}$ of dry soil.

The dry density of the soil can be measured in the field by removing a known volume of soil and measuring its dry weight in the laboratory or by using a nuclear density gage. It varies typically from 1,200 to $2,300 \mathrm{~kg} \cdot \mathrm{m}^{-3}$ and can be estimated from data on soil classification and penetration tests.

The emanation coefficient is sensitive to the moisture content of the soil. It can be measured in the laboratory, but it has been suggested [DSMA Atcon, 1983] that estimates should be used. It typically is on the order of 15 to $20 \%$ for dry soils and $35 \%$ for wet soils. However, in some instances emanation coefficients higher than 708 have been recorded.

The diffusion coefficient decreases with moisture content. It can be estimated closely by Eq (9) which was developed from a large data base. It varies from $7 \cdot 10^{-6} \mathrm{~m}^{2} \cdot \mathrm{s}^{-1}$ for dry soils to $2 \cdot 10^{-10} \mathrm{~m}^{2} \cdot \mathrm{s}^{-1}$ for saturated soils.

The permeability coefficient decreases with increasing moisture content. The coefficient of gas permeability for dry soils is an invariable quantity. it can be estimated from the particle size distribution and dry density of the soil or measured in the field or in the laboratory by various tests. It varies from $10^{-7}$ $\mathrm{m}^{2}$ for clean gravels to $10^{-18} \mathrm{~m}^{2}$ for clays.

\section{RADON SOURCE POTENTIAL INDEX}

\subsection{Radon Entry By Convective Flow}

Radon could enter a building in various ways, depending on the type of construction and the operation of the HVAC system. In this section an assessment of the relative effect of the subsoil permeability is made. 
Radon entry is in most instances through openings in basement slabs and walls. Typically, basement slabs are underlain by a sub-base of 4 inches or more of granular material which has a high gas permeability. If entry is through cracks and other openings in the basement slab or through joints between the slab and the foundation wall, which in most instances would be the case, the granular sub-base serves as a reservoir in which equipotential conditions are assumed in order to simplify the problem (actually some pressure gradients have been observed [DSMA Atcon, 1983]). There may or may not be a significant pressure drop between the sub-base and the interior of the basement, depending on the width of the openings through which the soil gas enters and the quantity of gas that enters through the openings. Radon entry could also occur through cracks in basement walls, which would result in a different convective-flow pattern.

The quantity of soil gas that enters a house as a result of a pressure gradient between the sub-base and its supporting and surrounding soil depends on the convective flow generated by the pressure gradient, which in turn depends on the permeability and thickness of the supporting soil.

As noted in the conclusions drawn from theoretical derivations in Section 2.2, the quantity of soil gas supplied in a given length of time as a result of a pressure gradient from the subsoil to the house is a function of $\mathrm{k}^{0.5}$ under transient flow conditions and a function of $k$ under steady-state flow conditions. This consideration directly affects the dimension of a radon index containing $\mathrm{k}$. It was also noted that the steady-state flow condition, which must follow a period of transient conditions, is a lower limit. Thus it is important to establish an approximate time scale which can be compared with the length of time of predicted cycles of pressure drop.

If it is assumed that: the soil permeability is $k$; the openings in the basement slab are large enough not to generate a significant pressure drop between the interior of the building and the sub-base of the slab; the thickness of the supporting soil layer is $H$ and the soil rests on impermeable bedrock; the lateral dimension of the house is much larger than the thickness of the soil layer; and the pressure drop occurs at time $t_{0}$ and continues for a length of 
time $t$; then the following equation can be derived from Eq(17) for 1-dimensional flow:

$$
t_{\mathrm{a}}=\mathrm{a}^{2} \mathrm{nH}^{2} \pi \cdot \frac{\mu}{4 \mathrm{kP}}
$$

where: $\quad t_{a}=$ time required to displace fraction a of the total quantity of gas that would be displaced from a prismatic soil column of height $H$ by a pressure drop $p_{0}$ below the initial atmospheric pressure $\mathrm{P}_{0}$.

Equation (27) is independent of $\mathrm{p}_{0}$. This is only true when Darcy's law is valid and the pressure drop is much smaller than the atmospheric pressure. Figure 4 shows a plot of $t_{a}$ values as a function of permeability, calculated for an a value of 0.5 , a $\mathrm{P}_{0}$ value of $1.013 \cdot 10^{5} \mathrm{~Pa}$, a $\mu$ value of $1.827 \cdot 10^{-5} \mathrm{~Pa} \cdot \mathrm{s}$ and an $\mathrm{n}$ value of 0.5 .

Note that it would take about five hours to displace half the pore gas that would be displaced from a 10-m (30-ft) thick column of silty sand by a given pressure drop, but only about three minutes to displace the same fraction of the soil gas from a 10-m thick column of well graded clean sand and gravel. However, it would take only one tenth of this time to displace half the soil gas from a 3-m (10-ft) thick layer, which would be about half an hour for a 3-m column of silty sand and about 20 seconds for a 3-m column of well graded sand and gravel. The time scale in figure 4 only applies when the lateral dimensions of the house are much larger than the height of the soil column. In reality, the effect of horizontal inflow of gas into the soil along the perimeter of the house would be to substantially prolong the duration of the transient flow conditions for the thicker soil layers.

Some data on observed fluctuations of pressure differences between the inside and outside of buildings are given by Turk et al., 1988, and Hubbard et al., 1988. From their data plots it appears that in summer, when pressure differences caused by diurnal temperature cycles and wind conditions fluctuate between positive and negative, transient flow conditions would predominate. This is also indicated by the results of mathematical simulations of wind effects by Scott Assoc., 1985 in which it was found (by a transient convectiveflow model) that radon entry is proportional to $\mathrm{k}^{0.45}$. In winter, however, because of the stack effect, there was an average negative pressure gradient from the outside to the interior of the building, in addition to pressure 


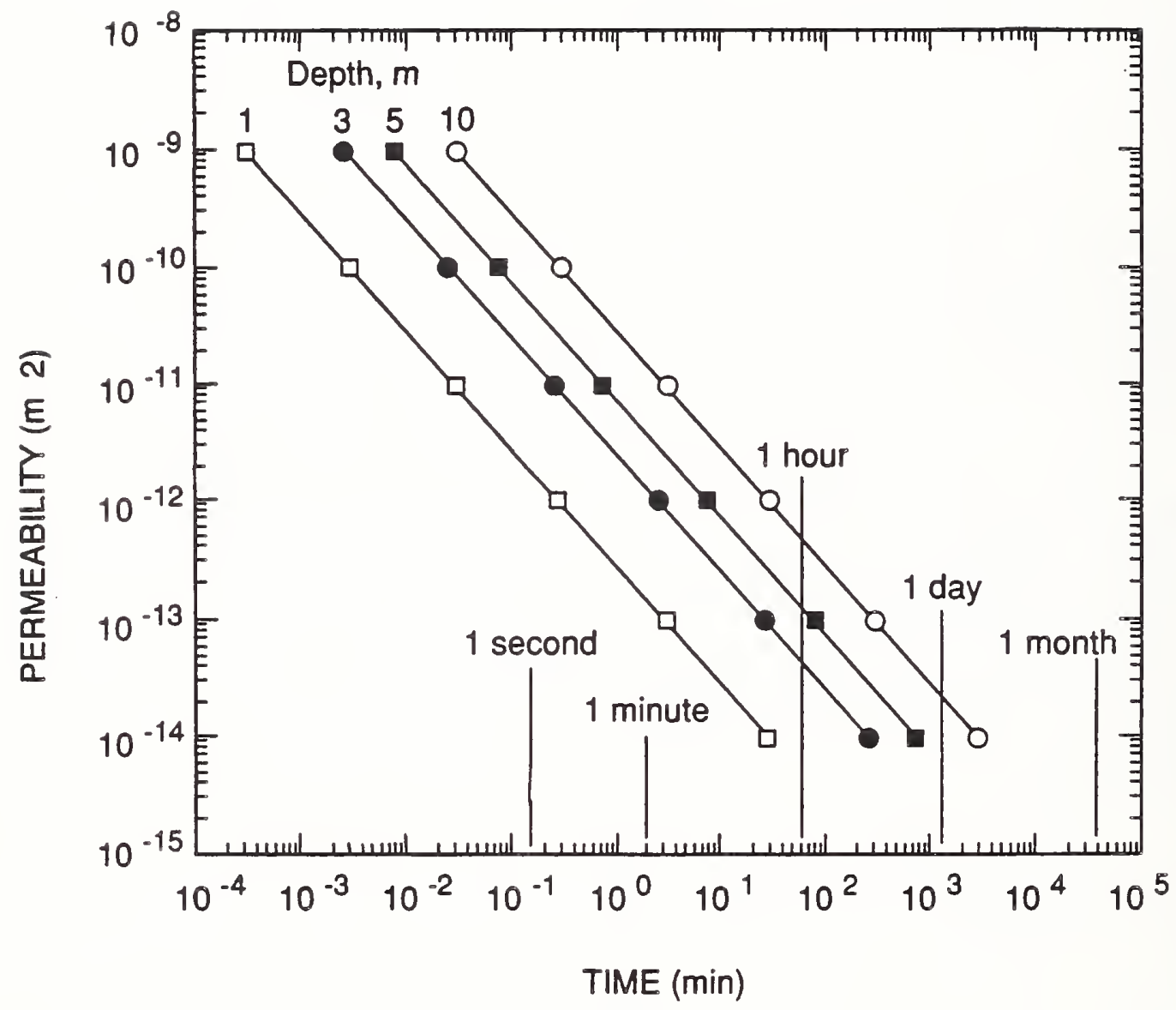

Figure 4: Time required to displace by 1-dimensional flow 508 of the soil gas that would be displaced by a pressure drop at time $t=0$. 
fluctuations which were of the same order of magnitude as the average. While there is a long-term negative pressure gradient into the house, the time scale of the soil response indicates that there will always be pressure fluctuations which will result in a significant transient flow component.

The steady-state flow occurs after a time $t$ which is long enough for the flow to stabilize. While the transient flow in its initial stages would be primarily along a flow path from the soil underlying the sub-base vertically upward into the sub-base, the steady-state flow would be along a path from the surface of the soil surrounding the building toward the sub-base through its surrounding and underlying soil. This latter flowpath would substantially contribute to the dilution of the radon concentration in the soil gas transported and thereby tend to reduce the effect of $k$ on the radon source potential.

\subsection{Expressions for Radon Source Potential.}

Several diagnostic procedures for the evaluation of radon source potential on the basis of measured soil properties have been proposed. These range from simple expressions which only consider invariant index properties of the soil, to more complex expressions which also consider the characteristics of the building. Most procedures utilize in situ measurements of soil permeability and soil gas radon concentration which are sensitive to barometric pressure, temperature, and moisture conditions at the time, as well as prior to the time the measurements are made.

Eaton and Scott, 1984, proposed a radon index number:

$$
\mathrm{RIN}=\frac{\mathrm{hA}_{\mathrm{Ra}}}{-\log \mathrm{k}}
$$

where: $h=$ air change period, hours.

In a later study with a mathematical model [DSMA Atcon, 1985] the same authors found that radon concentration varied as $k^{0.45}$ and suggested the following index:

$$
R=\log \left(A_{R a}\right)+0.45 \cdot \log (k)
$$


The authors suggest that if $\mathrm{A}_{\mathrm{Ra}}$ is expressed in $\mathrm{pCi} \cdot \mathrm{g}^{-1}$ and $\mathrm{k}$ in $\mathrm{cm}^{2}$ a number of $\mathrm{R}=-2.6$ would result in average radon concentrations of $2-3 \mathrm{pCi} / \ell$. Larger numbers would indicate higher average concentrations.

Another index number is proposed by Kunz et al., 1988 and backed up with data from glacial terrace deposits in New York State:

$$
\mathrm{RIN}=10 \cdot \mathrm{Cm} \cdot \mathrm{km}^{0.5}
$$

where: $\quad \mathrm{Cm}_{\mathrm{m}}=$ measured radon concentration in soil gas $\left(\mathrm{pC} i \cdot \ell^{-1}\right)$

$\mathrm{km}=$ measured gas permeability in $\mathrm{cm}^{2}$

The equation is calibrated to give average indoor radon concentrations in $\mathrm{pCi} / \ell$ and has been calibrated to match field data. For the data examined the equation seems to provide a reasonably good prediction of average measured indoor radon concentrations. Kunz et al. also report several interesting observations. An inverse relationship between the measured radon concentrations in the soil gas and the measured permeabilities was observed. This could be attributable to differences in moisture content (a higher moisture retention in soils with more fines) or to the effect of pressure-gradient induced convective flow from the atmosphere into the soil. It was also established that the radon concentrations in the soil gas increased with the distance from the house, probably because of dilution resulting from convective flow. Both of these observations indicate that the effects of increased convective flow are partially offset by decreased radon concentration in the soil gas.

For the same soil data, an index number can be derived in terms of invariant soil index properties. Assuming that:

$$
\begin{aligned}
& \mathrm{k}=2 \mathrm{~km} \text { (a moisture correction; "m" means "measured") } \\
& \mathrm{C}_{\max }=\mathrm{bCm}=0.35 \gamma_{\mathrm{d}} \mathrm{A}_{\mathrm{Ra}} \cdot \frac{1}{\mathrm{n}} \quad(\mathrm{b} \text { came out to be approximately 2.4) }
\end{aligned}
$$

And that for the conditions examined $\gamma_{\mathrm{d}}=1,800 \mathrm{~kg} \cdot \mathrm{m}^{-3}$ and $\mathrm{n}=0.4$, the following approximate radon index can be derived from the data presented by Kunz et al.:

$$
\mathrm{Y}=1.15 \gamma_{\mathrm{d}} \mathrm{A}_{\mathrm{Ra}} \cdot \mathrm{n}^{-1} \cdot \mathrm{k}^{0.5}
$$

where: $\quad \gamma_{\mathrm{d}}$ is in $\mathrm{kg} \cdot \mathrm{m}^{-3} ; \mathrm{A}_{\mathrm{Ra}}$ is in $\mathrm{Bq} \cdot \mathrm{kg}^{-1} ;$ and $\mathrm{k}$ is in $\mathrm{m}^{2}$.

Index $Y$ in Eq(31) is an expression for the ratio of the expected average indoor radon level to the EPA threshold level of $4 \mathrm{pCi} / \ell$. Thus if $Y \geq 1$ it is expected that, unless special precautions are taken, the EPA threshold level will be 
exceeded. $Y$ is calculated from the invariant index properties previously discussed, namely: the dry in-place density of the soil, the radium activity concentration, the porosity, and the dry gas permeability.

Except for Eq(28) which considers air change periods, the previous expressions do not consider the characteristics of the buildings, even though such consideration is implicit in the expressions developed. Other equations for source potential, however, also consider parameters associated with the building. A calculated potential in terms of activity per unit time $\left(\mathrm{pCi} \cdot \mathrm{h}^{-1}\right.$ or $\mathrm{Bq} \cdot \mathrm{s}^{-1}$ ) was presented by Nazaroff and Sextro, 1989. Source potential is defined as the "maximum sustainable entry rate" based on a specified indoor-outdoor pressure difference, isotropic soil characteristics, dominance of convective transport, and air penetration at the perimeter basement wall through cracks of an assumed widths:

For: $p_{0} k \leq 0.5 n \mu H^{2} \cdot \ln (2 \mathrm{H} / r)$

$$
\mathrm{F}=2 \pi \mathrm{C}_{\max } \cdot \frac{\mathrm{k}}{\mu} \cdot \frac{\mathrm{LPo}}{\ln (\mathrm{H} / \mathrm{r})}
$$

for larger values of $\mathrm{k}$ (approximately $\mathrm{k}>3.5 \cdot 10^{-11} \mathrm{~m}^{2}$ ):

$$
F=4 G \cdot\left(\frac{k}{\mu \lambda}\right)^{2 / 3} n^{1 / 3} \cdot\left(\frac{H}{\ln (H / r)}\right)^{2 / 3} \ldots
$$

where: $\quad H=$ depth of a perimeter crack between the basement slab and the wall below the grade outside the house

$r=$ half the width of a perimeter crack

$\mathrm{L}=$ length of the perimeter crack.

For a house with a $40 \mathrm{~m}$ perimeter crack in the basement, a $450 \mathrm{~m}^{3}$ volume and an air exchange rate of 2 hours, $F$ should not exceed $10 \mathrm{~Bq} \cdot \mathrm{s}^{-1}$.

Equations $32 \mathrm{a}$ and $\mathrm{b}$ were developed for steady-state flow, which account for the fact that the radon entry rate is directly proportional to $k$. When dimension $H$ is interpreted, account must be taken of the fact that the air flow is below the wall foundation. It was suggested in $\mathrm{Eq}(19)$ to add $1.5 \mathrm{~m}$ to $\mathrm{H}$ in order to account for this fact. A more reasonable approach may be to measure $H$ from the bottom of the footing. 
Equations 32 were purposely written in a way which separates the terms associated with site characteristics from those associated with building characteristics. These terms can be de-coupled for the purpose of site characterization.

Another approach to source potential determination was developed by Tanner, 1987. A "mean migration distance" is calculated by the following equation:

$$
M=\left[\frac{v}{2(n \lambda D) 0.5}+\left(\frac{v^{2}}{4 n \lambda D}+1\right)^{0.5}\right]\left[(n D) \lambda^{-1}\right] \ldots(33)
$$

$\mathrm{v}$ is taken such that $\mathrm{p}$ decreases linearly by $5 \mathrm{~Pa}$ over a distance of $4.6 \cdot \mathrm{M} / \mathrm{n}$ which is the distance over which the radon concentration would decay to $1 \%$ if the flow velocity is as in Eq(33). Solutions are obtained by iteration. A volume of soil is calculated by folding the foundation walls outward from the building and multiplying the projected area by $M$. The radon contained within the pore space of this volume is assumed to be the maximum available radon. The difference between this approach and approaches previously discussed is that diffusive as well as convective flow is considered. A potential problem envisioned is that the soil volume is a linear function of $\mathrm{k}$, while radon concentrations observed appear to be approximately proportional to $k^{0.5}$. The reason for this dimensional relationship is that a steady-state flow condition (linear pressure gradients) is used to derive $M$.

As in Eq(31), equations 32 and 33 can be expressed in terms of measurable invariant soil index properties. Assumptions would then have to be made to account for the effect of soil moisture content on permeability, diffusion, and radon concentration in the soil gas.

At the present time it would be premature to recommend one of the expressions discussed in this section and exclude the other expressions from consideration. This choice should be made after comparison with actual field data and some further parametric studies. Eqs.(28), (29), and (31) use invariant soil properties. Eq (30) would be similar to Eq (31) when modified to be used with invariant soil properties. Eqs. (32) and (33) could also modified to be used with invariant soil properties with an allowance for soil moisture content. 
Comparison with New-York State data [Kunz et al., 1988] indicates that the trend of the data is very well predicted by Eq (31), which was calibrated to fit the average value of the data (there is a good fit with individual data points).

A source potential measure based on invariant soil properties will have to take several conditions into consideration, probably in the form of modifiers. These include: climatological conditions such as rainfall, wind intensities, length of winter season and depth of frost cover; and soil profile characteristics such as drainage characteristics, depth to rock, soil stratification, location of phreatic surface and overconsolidation of the deposits.

\section{SITE EXPLORATION FOR RADON SOURCE POTENTIAL}

\subsection{Criteria}

Three criteria govern the procedures considered in this report.

(1) The site is characterized by soil index properties which do not vary as a result of transient conditions.

(2) The measurements should not depend on subjective judgment (though their interpretation involves professional judgment).

(3) While approximate procedures, such as manual-visual soil identification [ASTM D2488] or estimates of permeability by Table 5 are desirable for practical and economic reasons, accurate and repeatable methods such as ASTM D2487 and appropriate insitu and laboratory permeability tests that can be used as a backup in case of doubt or disputes must be identified.

\subsection{Options for Site Exploration}

Several options are outlined here on a preliminary basis. These options are not mutually exclusive. Neither are they intended as a substitute for present site exploration methods which measure in situ conditions existing at any given point in time. Rather, the proposed site exploration methods are intended to be used to provide information prior to construction and information which is 
independent of site conditions which may be temporary. One of the proposed methods can be readily integrated with the standard Penetration Test, which is presently the most commonly used soil exploration procedures.

\subsubsection{Test Borings}

The Standard Penetration Test [ASTM D 1586] is one of the most common soil exploration methods used in the U.S. Because it is so commonly used, it will be in many instances practical to combine its use for a routine geotechnical investigation with a determination of radon source potential. The test is also relatively inexpensive and equipment and trained personnel are readily available in any U.S. location.

The test drives a standardized sampler into the ground with a hammer which delivers a standardized amount of potential energy with each blow. A partially disturbed sample is retrieved which has a $13 / 8 \mathrm{in.}(35 \mathrm{~mm}$ ) diameter and is up to 18 inches ( $457 \mathrm{~mm}$ ) long. It is realistic to expect that a 5-inch (127 mm) long sample can in most instances be retrieved without difficulty. This provides a sample of approximately $200 \mathrm{~g}$ dry weight, large enough for radium activity concentration measurement by $\gamma$ - spectroscopy. The sample is also large enough for soil classification in accordance with ASTM D2487. Normal procedures include a field manual-visual soil classification by ASTM D2488, and a laboratory classification by ASTM D 2487. The test does not provide an accurate measurement of in situ dry density, because the sampler is driven into the ground, partially disturbing the soil. Density could be estimated from the driving resistance. Alternately, the height of the sample retrieved from the split-spoon sampler can be recorded in the field. Dry density can then be approximately determined in the laboratory. After completion of the laboratory classification, dry samples will be sealed and stored for 30 days for determination of radium activity concentration.

The test will provide a depth profile as required, from which the following information can be extracted: depth to rock (if needed), location of phreatic surface, $\gamma_{d}, n, A_{R a}, k$ (estimated from particle size distribution and density), natural moisture content, and Atterberg limits (if appropriate) which in turn 
can be used to determine swelling potential (propensity for fissure formation, refer to Table 4). It is also suggested, in addition to the Atterberg limit test, to perform a drying test [Yokel and Tucker, 1980] in order to supplement the information from the Atterberg limits. This information should be adequate for an approximate determination of the radon index. If desired, the saturation (m) can be estimated from the natural moisture content.

If the soil is finegrained, more accurate data can be obtained by retrieving an essentially undisturbed thin-wall tube sample in accordance with ASTM D1587. Such a sample will permit accurate laboratory determination of $\gamma_{d}, n$ and $k$. Examination of the sample in the laboratory can also provide clues on the presence of fissures.

More recently a "continuous sample tube system" has been introduced, in which a 3 inch (76 mm) O.D., $21 / 2$ inch (64 mm) I.D. core barrel is inserted in a hollow-stem auger to extract a $5 \mathrm{ft}(1.52 \mathrm{~m})$ long relatively undisturbed sample. This latter method permits extraction of relatively undisturbed samples of granular soils or desiccated clays. The sample allows a much more accurate determination of dry density than the SPT. These samples may also be used to detect fissures in fine grained soils and in some instances for laboratory permeability testing.

\subsubsection{Manual Procedure}

A simple manual procedure is also considered, particularly when an isolated site is explored where it would be expensive to bring in SPT equipment. The suggested procedure includes: measurement of the radium activity concentration with a portable $\gamma$-ray spectrometer; measurement of soil density and moisture content with a portable nuclear gage; manual-visual soil classification in the field; and retrieval of a soil sample (approximately $1 \mathrm{~kg}$ ) for laboratory soil classification. This procedure would provide a rapid and relatively inexpensive evaluation of radon source potential. However, readily available instruments would be mainly usable for surficial measurements (unless a test pit is dug). It is proposed to build portable down-hole spectrometers and density gages, which can be used in an auger hole. Such instruments have been developed, but they are 
not readily commercially available and their portability may have to be improved.

\subsubsection{Percolation Test}

Percolation tests [HUD Minimum Property Standards, 1973] which are routinely required for many rural building sites could be utilized to estimate permeability and integrated with the manual procedure in 2. This would improve the accuracy of the estimate of $\mathrm{k}$. However, a study is required to correlate test results with $\mathrm{k}$.

\subsubsection{Existing Radon Testing Protocols}

Existing radon testing protocols [i.e. Tanner, 1987] can be used to measure radon concentration in the soil gas and gas permeability, together with determinations of in situ moisture content and dry density. The results can than be corrected for moisture content to obtain an estimate of invariant index properties. $C_{m}$ can be measured at a great enough depth to provide a measure of $\mathrm{C}_{\max }$.

\subsubsection{Backup procedures}

In some instances, when the accuracy of field test interpretations is doubted or disputed, a more accurate procedures may be required to determine $k$. Several backup procedures are available. If the soil is dry or moist a soil gas permeability test (i.e. Tanner, 1987) can be conducted with an estimated correction factor for saturation. In wet soils this procedure would be inaccurate. Alternately, $\mathrm{k}$ can be determined by ASTM D2434 (constant head test) ASTM D2435, one-dimensional consolidation test, or horizontal capillary test [Lambe, 1958]. Water permeabilities will have to be corrected for the Klinkenberg effect (the correction factor ranges approximately from 1 for sands to 2 for silts). The horizontal capillary test results must additionally be corrected for partial saturation (a factor ranging from 2 to 3 ). 


\subsection{Selection of Exploration Procedure}

The exploration procedure selected in any particular instance would depend on several conditions. If a single, isolated housing site is involved, the manual procedure is probably the most practical, because it is expensive to mobilize the drilling equipment. The manual procedure would also be economical when percolation tests have to be conducted, because the two procedures can be combined. On the other hand, if many housing sites are involved there would be an economy of scale and the test boring procedure would be more practical. The test boring procedure is also an attractive and inexpensive option when the radon source potential test can be combined with a geotechnical exploration required for other purposes.

The test boring procedure has the advantage of providing a depth profile. While the manual procedure can also provide a depth profile, it may become expensive when the desired depth of exploration exceeds $1.5 \mathrm{~m}$.

\section{STANDARD DEVELOPMENT}

This study indicates that it is feasible and practical to develop testing protocols for the determination of invariant index properties of the subsoil associated with radon source potential. However, it is necessary to establish the credibility of a standard for the determination of the radon source potential of sites which is based on these invariant soil properties. The following program is proposed to accomplish this goal.

Phase I - Feasibility study: This stage is completed with this report.

Phase II- (a) Development of testing protocols

(b) Field and laboratory study (effect of moisture content on gas permeability, comparison of water and gas permeability, study of HUD percolation test, development and tryout of instrument packages)

(c) Parametric study (use transient model to assess effect of various parameters and examine existing source potential equations. 
Phase III- Data acquisition and verification of predictive models Phase IV - Preparation of draft standard

\section{Development of Testing Protocols:}

An outline of options is provided in Section 5.2. These options must be spelled out in more specific terms and procedures must be specified to avoid ambiguities and insure the quality control of the planned data acquisition.

\section{Field and Laboratory Studies:}

Effect of moisture content: Present data on the effect of saturation on air permeability are inadequate. A well controlled laboratory study is needed to provide a data base similar to that which exists for moisture effects on the diffusion coefficient.

Study of Klinkenberg effect: dry gas and saturated water permeabilities need to be compared for different soil types to provide a reliable data base for converting water permeabilities to gas permeabilities at atmospheric pressure.

HUD Percolation Test: No study could be located to correlate the test with permeability. Also, specifications for the test should be tightened. A similar test was extensively used by the Bureau of Reclamation [Bureau of Reclamation, 1963] and can be correlated with permeability, however the latter test uses a cased hole and a larger water head and requires a drill rig. It is not clear whether the cost of the test would substantially increase if the BUREC test were used. A study, including field data acquisition, and an appropriate analytical model for the test is needed.

Development of Instrument Package: a portable downhole spectrometer and a downhole nuclear moisture-density gage are needed. These instruments would not only be useful for the manual procedure outlined in 5.2, but they could also be used together with the Tanner protocol and in conjunction with the proposed SPT procedure. 


\section{Parametric Study}

It is proposed to use a computer code combining transient convective flow with diffusion and radon generation to test the source potential models described in Section 4 and if appropriate develop a new model. The calculation will converge to steady-state convective flow if the duration of the pressure drop is long enough.

\section{Data Acquisition and Verification}

The testing protocols developed in Phase II will be used to determine the relevant invariant soil parameters for sites where extensive radon data are available. On some of the sites, presently-used in situ exploration protocols (i.e. Tanner, 1987) will be used along with the testing protocols developed in Phase II to obtain comparative data. The sites selected will include sites where radon measurements are presently performed by Federal agencies and other sites where data are available. An initial quick pilot study will be conducted to insure that the data sample will cover a sufficiently broad range of soil permeabilities and other characteristics.

The results of the study will be plotted against various equations for source potential to determine how well they predict the source potential in the data sample. A best fit source potential equation will be developed.

\section{Preparation of Draft Standard}

A draft standard for site characterization will be proposed. The standard will include alternate testing protocols and methods of determining source potential.

\section{ACKNOWLEDGEMENT}

Comments and suggestions from Dr. Arthur Scott and professor William W. Nazaroff are gratefully acknowledged. 
[1] Arulmoli, K., Arulanandan, K., and Seed, H.B. New Method for Evaluating Liquefaction Potential, J.Geotechnical Engineering, ASCE, III, No.1, Jan. 1985, 95-114.

[2] ASTM D 698-78, "Standard Test Method for Moisture-Density Relations of Soil and Soil-Aggregate Mixtures Using 5.5-lb (2.49-kg) Rammer and 18-in. (457mm) Drop", ASTM V. 04.08, 1988.

[3] ASTM D 1556-82, "Standard Test Method for Density of Soil In Place by the Sand Cone Method", ASTM V. 04.08, 1088

[4] ASTM D 1557-78, "Standard Test Method for Moisture-Density Relations of Soil and Soil Aggregate Mixtures Using 10-1b (4.54-kg) Rammer and 18-in (457-mn) Drop", ASTM V. 04.08, 1988.

[5] ASTM D 1586-84, "Standard Test Method for Penetration Test and Split Barrel Sampling of Soil", ASTM V. 04.08, 1988.

[6] ASTM D 1587-83, "Standard Test Method for Thin-Wall Tube Sampling of Soils", ASTM V.04.08, 1988.

[7] ASTM D 2487-85, "Standard Test Method for Classification of Soils for Engineering Purposes", ASTM V.04.08, 1988.

[8] ASTM D 2488-84,"Standard Practice for Description and Identification of Soils", ASTM V. 04.08, 1988.

[9] ASTM D 2922-81' "Standard Test Methods for Density of Soil and SoilAggregate in Place by Nuclear Methods (Shallow Depth)", ASTM V. 04.08, 1988 .

[10] ASTM D 3441-86, "Standard Test Method for Deep, Quasi-Static, Cone and Friction-Cone Penetration Tests of Soil", ASTM V. 04.08, 1988.

[11] ASTM D 4318-84, "Standard Test Method for Liquid Limit, Plastic Limit, and Plasticity Index of Soils", ASTM V. 04.08, 1988.

[12] Bosscher, P.J., Bruxvoort, G.P. and Kelley, T.E. Influence of Discontinuous Joints on Permeability, J. Geotechnical Engineering, ASCE 114, No.11, November 1988.

[13] Bureau of Reclamation, Earth Manual, First Edition-Revised, U.S. Government Printing Office, 1963. 541. 2nd Ed. 1974.

[14] Cedergren, H.R. Seepage Drainage and Flow Nets, New York, John Wiley \& Sons, 1967.

[15] Carslaw, H.S. and Jaeger, J.C. Operational Methods in Applied Mathematics, Oxford University Press, 1941. 
[16] Carslaw, H.S. and Jaeger, J.C. Conduction of Heat in Solids, London, U.K., Oxford at the Clarendon Press, 1959.

[17] Casagrande, A. and Fadum, R.E. Application of Soil Mechanics in Designing Building Foundations, Transactions ASCE, 109, 1944. 383-490.

[18] Clements, W.E. The Effect of Atmospheric Pressure Variation on the Transport of $\mathrm{Rn}^{222}$ From the Soil to the Atmosphere, Ph.D Dissertation, New Mexico Institute of Mining and Technology, Socorro, NM, Feb. 1974.

[19] Corey, A.T. Mechanics of Immiscible Fluids in Porous Media, Water Resources Publications, Fort Collins, CO 1988.

[20] Darcy, H. Les Fontaines Publiques de la Ville de Dijon, Paris:V, Dalmonte, 1856.

[21] DSMA Atcon, Ltd., Review of Existing Instrumentation and Evaluation of Possibilities For Research and Development of Instrumentation to Determine Future Levels of Radon at a Proposed Building Site, Atomic Energy Control Board, Ottawa Canada, January 1983.

[22] Dupuis, J. Etudes Theoretiques et pratiques sur le mouvement des Aux, Paris, 1863.

[23] Eaton, R.S. and Scott, A.G. Understanding Radon Transport into Houses, Radiation Protection Dosimetry, 7(4), 1984. 251-253.13

[24] Fukuda, H. Air and Vapor Movement in Soil due to Wind Gustiness, Soil Science 79, 249.

[25] Gundersen, L.C.S., G.M. Reimer, C.R. Wiggins, C.A. Rice, Radon Potential of Rock and Soil in Montgomery County, MD, U.S.G.S. Report MS-2043, 1988.

[26] Hansbo, S.,Consolidation of Clay with Special Reference to the Influence of Vertical Sand Drains, Proc. Swedish Geotechnical Inst. V.18, 1960.

[27] Harr, M.E. Groundwater and Seepage, New York, McGraw-Hill Book Co., 1962.

[28] Hazen, A. Annual Report of the Massachusetts State Board of Health, 1892.

[29] Herzog, B.L. and Morse, W.J. A Comparison of Laboratory and Field Determined Values of Hydraulic Conductivity at a Waste Disposal Site, 7th Annual Madison Waste Conference, U. of Wisconsin, Madison WI 1984, 30-52.

[30] Hubbard, L.M., Bolker, B., Socolow, R.H. Radon Dynamics in a House Heated Alternately By Forced Air and by Electric Resistance, Symp. on Radon and Radon Reduction Technology, Denver CO, Oct. 17-21, 1988, Paper VI-1.

[31] Klinkenberg, L.J. The Permeability of Porous Media to Liquids and Gases, American Petroleum Institute, Drilling and Production Practice, 1941. 200212 . 
[32] Kunz, C.; Laymon, C.A.; Parker, C. Gravelly Soils and Indoor Radon, Symp. on Radon and Radon Reduction Technology, Denver CO, Oct. 17-21, 1988 , Paper V-6.

[33] Lambe, T.W. Soil Testing for Engineers, New York, John Wiley \& Sons, Inc., fifth printing, 1958.

[34] Lambe, T.W. and Whitman, R.V. Soil Mechanics, New York: John Wiley \& Sons, 1969.

[35] Leonards, G.E., ed. Foundation Engineering, New York, McGraw-Hill Inc., 1962 .

[36] Long, J.C.S. et al. Porous Media Equivalents for Networks of Discontinuous Fractures, Water Resources Research 18(3) 1982. 645-658.

[37] Matthews, D.L. et al. Radon Diagnostics: Subslab Communication and Permeability Measurements, Proc. Symp. on Radon and Radon Reduction Reduction Technology, Denver CO, Oct. 17-21, 1988, Paper VI-4.

[38] McKinlay D.G. et al.Representative Sampling and Testing of Fissures Lodgement Tills, The Engineering Behavior of Glacial Material, 2nd Ed. Midland Soil Mech. and Found. Soc., U. of Birmingham, Birmingham U.K. 1978. 129-140.

[39] Milligan, V. Field Measurement of Permeability in Soil and Rock, Proc. Conf. on In Situ Measurement of Soil Properties, Raleigh NC June 1-4,1975, ASCE, 1976 II, 3-36.

[40] Mowris, R.J. and Fisk, W.J. Modeling the Effects of Exhaust Ventilation on ${ }^{222} \mathrm{Rn}$ Entry Rates and Indoor ${ }^{222} \mathrm{Rn}$ Concentrations, Health Physics 54(5), 1988. 491-501.

[41] Nazaroff, W.W., Moed, B.A., and Sextro, R.G., Soil as a Source of Radon: Generation, Migration, and Entry, in Nazaroff, W.W.; Nero, A.V. Jr., eds., Radon and its Decay Products in Indoor Air, New York: John Wiley and Sons; 1988.

[42] Nazaroff, W.W. and Sextro, R.G. Technique for Measuring the Indoor ${ }^{222}$ Rn Source Potential of Soil, Environmental Science and Technology 23(4) 1989. 451-458.

[43] Oliveira Lourero, C., Simulation of Steady-state Transport of Radon from Soil into Houses with Basements Under Constant Negative Pressure, Dissertation, University of Michigan, Lawrence Berkeley Laboratory, Berkeley, CA, 1987.

[44] Pavlovsky, N.N. Collected Works, Akad. Nauk, Leningrad, USSR, 1956.

[45] Rogers, V.C., and Nielson, K.K., Radon Emanation and Transport in Porous Media, Symp. on Radon and Radon Reduction Technology, Denver, CO, Oct. 1721, 1988, Paper V-4. 
[46] Schery, S.D., Gaeddert, D.H., and Wikening, M.H. Factors Affecting Exhalation of Radon From a Gravelly Sandy Loam, J. of Geophysical research, Vo.89, No. D5, August, 1984. 7299-7309.

[47] Schumann, R.R.; Owen, D.E.; Asher-Bolinder, S. Weather Factors Affecting Soil-Gas Radon Concentrations at a Single Site in the Semiarid Western U.S., Symp. on Radon and Radon Reduction Technology, Denver CO, Oct. 17-21 1988, Paper V- P2.

[48] Scott A. and Associates, A Computer Study of Soil Gas Movement into Buildings, Rep. 1389/1333, Dept. of Health and Welfare, Ottawa, Canada, March, 1985.

[49] Sextro, R.G.; Nazaroff, W.W.; Turk, B.H. Soil Permeability and Radon Concentration Measurements and a Technique for Predicting a Radon Source Potential of Soil, Symp. on Radon and Radon Reduction Technology, Denver CO, Oct. 17-21, 1988, Paper V-5.

[50] Snow, D.T. Anisotropic Permeability of Fractured Media, Water Resources Res. 5(6) 1273-1289.

[51] Strong, K.P. and Levins, D.M. Effect of Moisture Content on Radon Emanation from Uranium Ore Tailings, Health Physics, 42, 1982, 27.

[52] Surback, H. and Piller, G. A Closer Look at the Natural Radioactivity of Soil, Symp. on Radon and Radon Reduction Technology, Denver, Co Oct. 17-21 1988 .

[53] Tanner, A.B. Radon Migration in the Ground, in J.A.S. Adams and W.M. Lowder, (eds.), Natural Radiation Environment, U. of Chicago Press, Chicago, 1964. 1651.

[54] Tanner, A.B. Radon Migration in the Ground: A Supplementary Review. In T.F. Gesell and W.M. Lowder, (eds.), Proc. National Radiation Environment III, Conf. 780422, NTIS, Springfield, VA, 1980. 5.

[55] Tanner, A.B. Measurement of Radon Availability from Soil. Marikos, M.A.; Hansman, R.H., ed. Geologic Causes of Natural Radionuclide Anomalies, Proc. GEORAD Conf., St Louis MO, Apr. 21-22. 1987, Mo. Dept. of Nat. Resources, Div. of Geology and Land Survey, Spec. Pub. No.4. 139-146.

[56] Terzaghi, K. Theoretical Soil Mechanics, Chapter XIII, Art. 102 (10), New York: John Wiley \& Sons, 8th. Ed.; 1956, 284.

[57] Turk, B.H. et al. Interim Report on Diagnostic Procedures for Radon Control, LBL-23089, Lawrence Berkeley laboratory, March 1987.

[58] Vaswani, N.K. Nuclear Measurement of Subgrade Moisture, Proc. Conf. on In Situ Measurement of Soil Properties, Raleigh, NC June 1-4 1975, ASCE, 1975 , I, 477-496. 
[59] Wadach, J.B., Hess, C.T. Radon-222 Concentration Measurements in Soil Using Liquid Scintillation and Track Etch, Health Physics, 48 No.6 1985. 805-808.

[60] Yokel, F.Y. and Mayne, P.W. Helical Probe Tests for Shallow Soil Exploration, NBSIR 86-3351, National Bureau of Standards, Gaithersburg MD, 1989.

[61] Yokel F.Y. and Tucker, R.L. Soil Classification for Construction Practice in Shallow Trenches, NBS Building Science Series 121, National Bureau of Standards, March 1980. 46. 


\section{Site Characterization for Radon Source Potential}

5. AUTHOR(S)

Felix Y. Yokel

6. PERFORMING ORGANIZATION (If joint or other thon NBS, see instructions)

7. Contracu Grant No.

NATIONAL BUREAU OF STANDARDS
U.S. DEPARTMENT OF COMMERCE
GAITHERSBURG, MD 20899

8. Type of Report \& Period Covered

9. SPONSORING ORGANIZATION NAME AND COMPLETE ADDRESS (Street. City. Stote, ZIP)

Dept of Housing \& Urban Development

Innovative Projects \& Special Technology Division

Washington, D.C. 20410

10. SUPPLEMENTARY NOTES

Document describes a computer program; SF-185. FIPS Software Summary, is attached.

11. ABSTRACT (A 200-word or less factual summory of most significant information. If document includes a significant bibliography or literoture survey. mention it here)

Radon source potential characterization of sites in terms of soil index properties which do not vary with transient conditions such as moisture content, barometric pressure, temperature and wind speed is studied. The invariant index properties which were found to be critical for site characterization are radium activity concentration in the soil, in-place dry density, porosity, and dry gas permeability. These properties can be measured in situ or in the laboratory, or estimated on the basis of other soil index properties such as grain-size distribution and Atterberg limits. Various expressions for radon source potential are reviewed and a new expression is formulated on the basis of data from areas of deep glacial terrace deposits. Site exploration methods proposed include use of the Standard Penetration Test together with a laboratory determination of radium activity concentration, and a rapid field measurement procedure using a portable gamma ray spectrometer, a portable nuclear moisturedensity meter and retrieval of a soil sample for laboratory determination of particle-size distribution. A plan to develop exploration protocols, test the effectiveness of the source potential prediction, and prepare a draft exploration standard is proposed.

12. KEY WORDS (Six to twelve entries: alphabetical order: copitalize only proper names; and separate key words by semicolons) Keywords: convective flow; diffusion; insitu measurements; soil exploration; permeability; porous media; radium activity concentration; radon; radon source potential.

13. AVAILABILITY

XXXnlimited

For Official Distribution. Do Not Release to NTIS

Order From Superintendent of Documents, U.S. Government Printing Office, Washington, D.C. 20402.

14. NO. OF

PRINTED PAGES

62

XXXrder From National Technical Information Service (NTIS), Springfield, VA. 22161

15. Price

$\$ 14.95$ 
